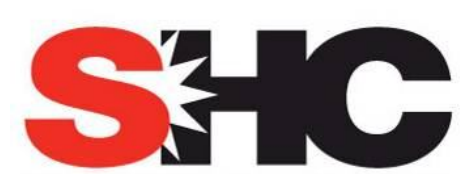

\title{
Task 48
}

\section{Final Deliverable}

\section{Pumps Efficiency and Adaptability}

Date: 12.02.2015

\section{By Martin Helm ${ }^{1}$}

${ }^{1}$ Institution Bavarian Center for Applied Energy Research (ZAE Bayern)

Address Walther Meissner Strasse 6, 85748 Garching, Germany

Phone +49-89-329442-33

e-mail_martin.helm@zae-bayern.de

With the support of

Anita Preisler ${ }^{2}$, Daniel Neyer ${ }^{3}$ and Alexander Thuer $^{3}$, Romain Siré ${ }^{4}$, Mathias Safarik ${ }^{5}$, Moritz Schubert ${ }^{6}$, Bettina Nocke ${ }^{7}$, Hilbert Focke ${ }^{8}$, Khalid Nagidi ${ }^{9}$, Dirk Petruschka ${ }^{10}$;

\begin{tabular}{|c|c|}
\hline${ }^{2}$ Institution & Australian Institute of Technology (AIT) \\
\hline Address & Giefinggasse 2, A-1210 Vienna, Austria \\
\hline Phone & $+43-50-550-6634$ \\
\hline e-mail & anita.preisler@ait.ac.at \\
\hline${ }^{3}$ Institution & University of Innsbruck (UIBK) \\
\hline Address & Technikerstrasse 13, A-6020 Innsbruck, Austria \\
\hline Phone & $+43-512-507-63651$ \\
\hline Phone & $+43-512-507-63653$ \\
\hline e-mail & daniel.neyer@uibk.ac.at \\
\hline e-mail & alexander.thuer@uibk.ac.at \\
\hline
\end{tabular}




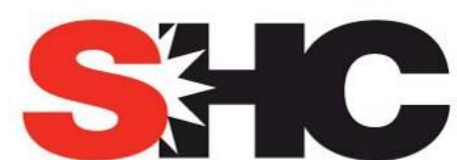

SOLAR HEATING \& COOLING PROGRAMME INTERNATIONAL ENERGY AGENCY

IEA SHC Task 48 / task48.iea-shc.org

\title{
Task 48
}

\author{
${ }^{4}$ Institution TECSOL \\ Address $\quad 105$ av Alfred Kastler -Tecnosud, F-66000 Perpignan, France \\ Phone +33-4-68-68-16-40 \\ e-mail_romain@tecsol.fr \\ ${ }^{5}$ Institution Institute of Air Handling and Refrigeration (ILK) \\ Address Bertolt-Brecht-Allee 20, D-01309 Dresden, Germany \\ Phone +49-351-4081-700 \\ e-mail_mathias.safarik@ilkdresden.de \\ ${ }^{6}$ Institution Gesellschaft für Solarinstallation und Design GmbH(SOLID) \\ Address Puchstrasse 85, A-8020 Graz, Austria \\ Phone +43-316-292840-81 \\ e-mail_m.schubert@solid.at \\ ${ }^{7}$ Institution AEE - Institut für Nachhaltige Technologien \\ Address Feldgasse 19, A-8200 Gleisdorf \\ Phone +43-3112 5886-221 \\ e-mail b.nocke@aee.at \\ ${ }^{8}$ Institution Austrian Solar Innovation Center (ASiC) \\ Address Ringstraße 43a, A-4020 Wels, Austria \\ Phone +43-7242-9396-5563 \\ e-mail_focke.hilbert@asic.at \\ ${ }^{9}$ Institution Energy Management Consulting Group, LLC (EMCG) \\ Address 844 Oakfield Ave, Ste 101, Wantagh, NY11793, USA \\ Phone +1516 308-4104 \\ e-mailＫhalid.nagigi@energymcg.com \\ ${ }^{10}$ Institution Hochschule für Technik Stuttgart \\ Address Schellingstrasse 24, D-70174 Stuttgart, Germany \\ Phone +49-711-8926-2674 \\ e-mail_dirk.pietruschka@hft-stuttgart.de
}




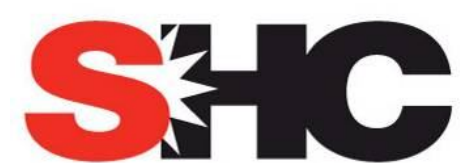

SOLAR HEATING \& COOLING PROGRAMME INTERNATIONAL ENERGY AGENCY

IEA SHC Task 48 / task48.iea-shc.org

\section{Task 48}

\section{IEA Solar Heating and Cooling Program}

The Solar Heating and Cooling Programme was founded in 1977 as one of the first multilateral technology initiatives ("Implementing Agreements") of the International Energy Agency. Its mission is "to enhance collective knowledge and application of solar heating and cooling through international collaboration to reach the goal set in the vision of solar thermal energy meeting $50 \%$ of low temperature heating and cooling demand by 2050.

The member countries of the Programme collaborate on projects (referred to as "Tasks") in the field of research, development, demonstration (RD\&D), and test methods for solar thermal energy and solar buildings.

A total of 53 such projects have been initiated to-date, 39 of which have been completed. Research topics include:

A Solar Space Heating and Water Heating (Tasks 14, 19, 26, 44)

A Solar Cooling (Tasks 25, 38, 48, 53)

A Solar Heat for Industrial or Agricultural Processes (Tasks 29, 33, 49)

A Solar District Heating (Tasks 7, 45)

A Solar Buildings/Architecture/Urban Planning (Tasks 8, 11, 12, 13, 20, 22, 23, 28, 37, 40, 41, 47, 51, 52)

A Solar Thermal \& PV (Tasks 16, 35)

A Daylighting/Lighting (Tasks 21, 31, 50)

A Materials/Components for Solar Heating and Cooling (Tasks 2, 3, 6, 10, 18, 27, 39)

A Standards, Certification, and Test Methods (Tasks 14, 24, 34, 43)

A Resource Assessment (Tasks 1, 4, 5, 9, 17, 36, 46)

A Storage of Solar Heat (Tasks 7, 32, 42)

In addition to the project work, there are special activities:

$>$ SHC International Conference on Solar Heating and Cooling for Buildings and Industry

$>$ Solar Heat Worldwide - annual statistics publication

$>$ Memorandum of Understanding with solar thermal trade organizations

$>$ Workshops and conferences

\section{Country Members}

Australia

Austria

Belgium

China

Canada

Denmark

European Commission

Sponsor Members

European Copper Institute ECREEE
Germany

Finland

France

Italy

Mexico

Netherlands

Portugal

Gulf Organization for Research and Development RCREEE

Singapore

$$
\text { South Africa }
$$

Spain

Sweden

Turkey

United States

Switzerland

United Kingdom

Research and Development 


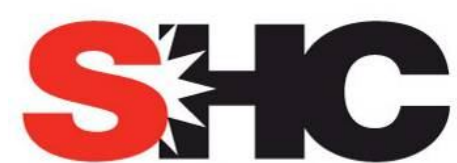

SOLAR HEATING \& COOLING PROGRAMME INTERNATIONAL ENERGY AGENCY

IEA SHC Task 48 / task48.iea-shc.org

\section{Task 48}

\section{Contents}

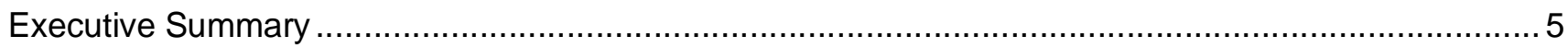

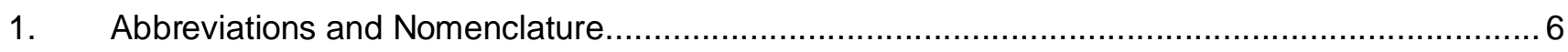

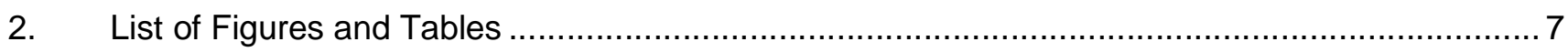

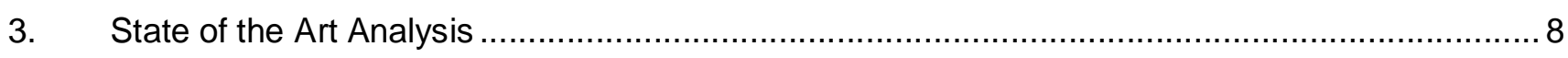

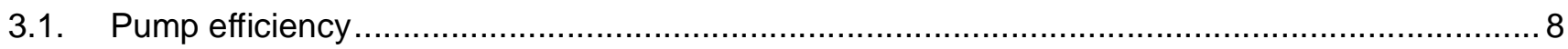

3.2. Thermodynamic and hydraulic design criteria of solar driven chillers.................................... 9

3.3. Hydraulic circuits and auxiliary electricity consumption in SHC-systems .............................. 12

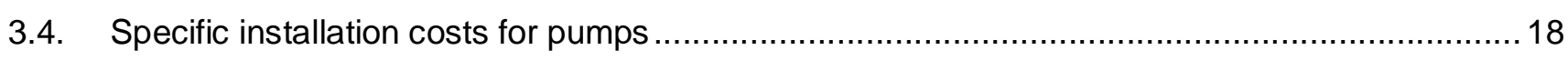

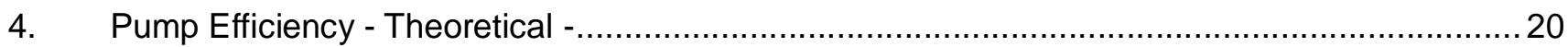

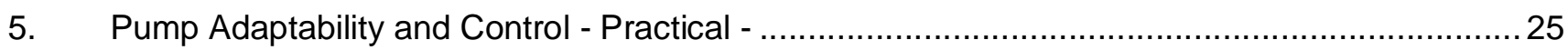

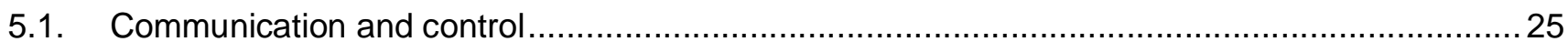

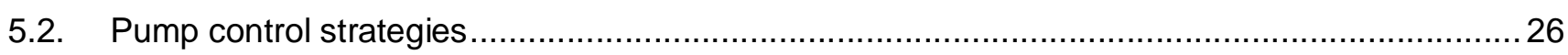

5.3. Operating points and overall efficiency under real operating conditions................................ 29

6. Design Guidelines and Best Practice for Efficient Hydraulics............................................... 34

6.1. Guidelines for hydraulic design and pump selection .................................................... 34

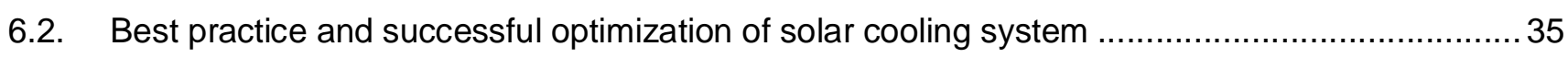

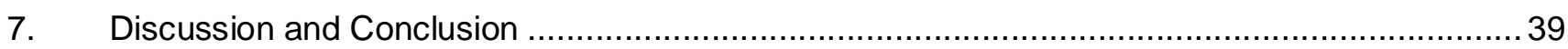

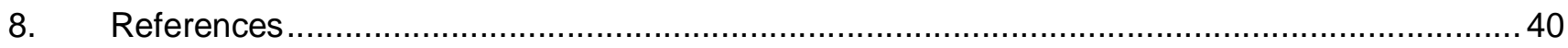

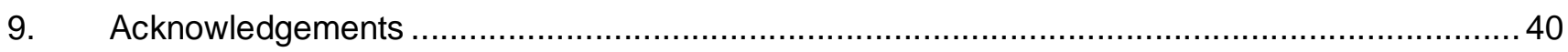




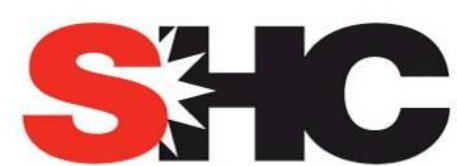

SOLAR HEATING \& COOLING PROGRAMME INTERNATIONAL ENERGY AGENCY

IEA SHC Task 48 / task48.iea-shc.org

\section{Task 48}

\section{Executive Summary}

Subtask A concentrates on developing tools and deliverables permitting to show the level of quality of the most critical components of the solar cooling and heating system. These components are mainly the chiller, the heat rejection device, the pumps and the solar collectors.

This technical report focuses on pump efficiency and adaptability to part load conditions in order to minimize the electricity consumption in the hydraulic circuits to obtain a high seasonal energy efficiency ratio in solar cooling systems.

In a first step a selection of market available chillers is evaluated by manufacturer design data concerning temperature differences, flow rates and pressure drops of the external hydraulic circuits and the resulting auxiliary energy electricity consumption to overcome the friction losses in the heat exchangers. While the EER for the chiller solely varies between 11.9 and 77.6 some market available chillers inherently impede good seasonal performance of the overall SHC-System.

Subsequently the different hydraulic circuits of several measured solar cooling systems are analyzed concerning their portion on the overall seasonal electricity consumption. Typically more than $50 \%$ of the auxiliaries are caused by the heat rejection system including cooling water pumps and fan.

A short observation of the portion of pump costs in SHC-Systems confirms the almost negligible impact on overall investment costs and absence of meaningful cost-saving opportunities. Furthermore due to substantially reduced operation costs high-efficiency pumps help to reduce operational costs.

But the deployment of high-efficiency pumps in solar cooling installations does not implicate an efficient pumping automatically. The strong relationship between pump and plant curve demands a proper system design and pump selection.

The way things are an overall SEER of 20 for well-designed small scale solar cooling systems and more seems to be feasible.

\section{Specific Objectives}

A state of the art analysis will be conducted on this component in close cooperation with ongoing IEASHC Tasks 44 and 45, where these issues are tackled as well. Furthermore the design criterions of market available chillers concerning temperature levels and pressure drop in the heat exchangers are assessed.

In addition to that a performance coefficient called Auxiliary Energy Consumption Ratio (AECR) for the overall hydraulic efficiency is introduced in order to compare the design of various hydraulic circuits of SHC-systems in different capacity classes.

A short theoretical introduction into the rotodynamic pump design helps to avoid planning errors, adverse duty points and simplifies a correct pump selection.

A particular focus will be addressed to the adaptability of the technology to part load production conditions.

Finally an investigation will be done on the best practices for electric consumption reduction for pumping in the different hydraulic loops of a solar cooling system. Best practice will be valorized always including the compromise between efficiency and simplicity. 


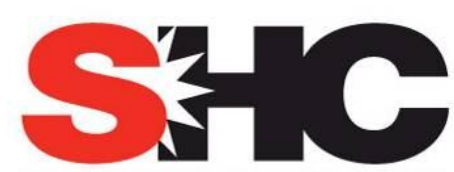

IEA SHC Task 48 / task48.iea-shc.org

\section{Task 48}

\section{Abbreviations and Nomenclature}

\section{Abbreviations}

AECR

AC

BEP

BUS

COP

$\mathrm{D}$

E

EuP

EEI

EER

$\mathrm{HQ}$

ICA

IEA

ISO

NPSH

SEER

$\mathrm{SHC}$

SPF

\section{Nomenclature}

$\mathrm{H}$

$P_{1}$

$\mathrm{P}_{2}$

$\mathrm{P}_{\mathrm{H}}$

$\mathrm{Q}$

$\mathrm{n}$

$\mathrm{H}$

$\eta_{M}$

$\eta_{\text {FC }}$
Auxiliary energy consumption ratio

Absorber, Adsorber \& Condenser

Best efficiency point

Binary Unit System

Coefficient of performance

Desorber

Evaporator

Energy using Products

Energy efficiency index

Energy efficiency ratio

Head and flow

Instrumentation, control and automation

International energy agency

International Organization for Standardization

Net positive suction heat

Seasonal energy efficiency ratio

Solar heating and cooling

Seasonal performance factor

Pump Head

Electric to pump

Mechanical shaft power to pump

Hydraulic power

Pump flow

Rotation speed

Pump efficiency

Electric motor efficiency

Frequency converter efficiency 


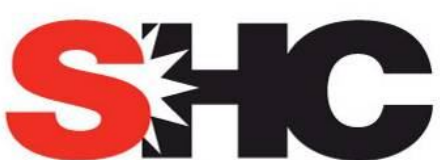

SOLAR HEATING \& COOLING PROGRAMME INTERNATIONAL ENERGY AGENCY

IEA SHC Task 48 / task48.iea-shc.org

\section{Task 48}

\section{List of Figures and Tables}

Figure 1: Pump efficiency at optimum specific speed for certain pump flows (Source: European

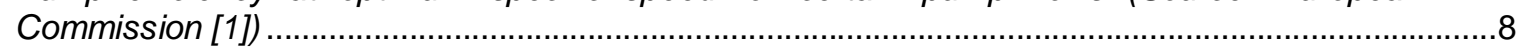

Figure 2: $\quad$ Task38 monitoring procedure (left) and generic system schemes (right).......................................12

Figure 3: Auxiliary Energy Consumption Ratios in the main hydraulic circuits solar array, Heat supply to chiller, cooling and chilled water of some SHC-systems

Figure 4: Characteristic cost distribution in SHC systems with absorption chillers.(Source: [3])......................18

Figure 5: Investment costs in a $10 \mathrm{~kW}$ absorption cooling system with dry heat rejection................................18

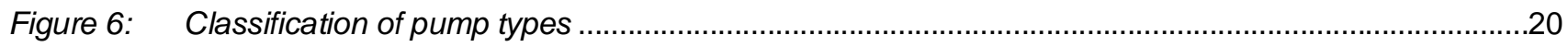

Figure 7: Sectional view of a canned rotodynamic pump. Source: Pump handbook [6] .................................21

Figure 8: Sectional view of a shafted rotodynamic pump. Source: Pump handbook [6] .................................21

Figure 9: $\quad$ QH map and system characteristic of a pump system. Based on: Pump handbook [6]....................23

Figure 10: QH map and system characteristic of a pump system. Based on:Pump handbook [6]....................23

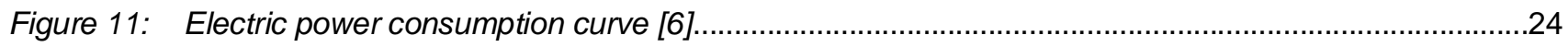

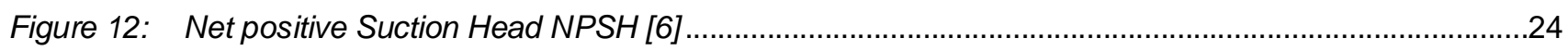

Figure 13: Characteristic $H Q$ and power diagrams with real operating points of circulators implemented in the hydraulic subsystems of a 7.5 chilled water capacity SHC system ..........................................30

Figure 14: Characteristic $H Q$ and power diagrams of solar primary pump and its operating points....................30

Figure 15: Characteristic HQ diagrams of primary and secondary pump in the cooling water circuit.................32

Figure 16: Characteristic $H Q$ and power diagrams of chilled water pump at different operating points...............33

Figure 17: Distribution of auxiliary energy consumption and stepwise optimization results..............................35

Figure 18: Daily insolation on collector surface and ambient temperatures (max, min, average) .......................36

Figure 19: Daily thermal COP including start up and shutdown phases..........................................................36

Figure 20: Daily EER for chilled water production including all electricity consumer of the SHC System ...........37

Figure 21: Daily auxiliary energy consumption ratios of the solar collector circuit............................................37

Figure 22: Daily auxiliary energy consumption ratios $A E C R_{A C}$ of the cooling water circuit................................38

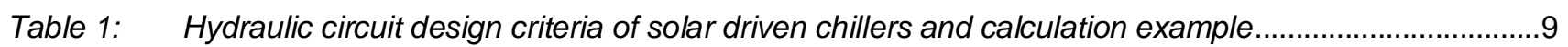

Table 2: $\quad$ Proportion of electricity consumption in the different sub-systems ................................................14

Table 3: $\quad$ Predominant rotodynamic pump types, canned and shafted, installed in SHC systems....................20 


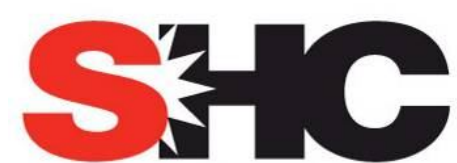

SOLAR HEATING \& COOLING PROGRAMME INTERNATIONAL ENERGY AGENCY

IEA SHC Task 48 / task48.iea-shc.org

\section{Task 48}

\section{State of the Art Analysis}

In general transferring thermal energy in solar cooling systems from one component to the others demands a certain heat transfer medium flow depending on the specific heat capacity and temperature spread between supply and return flow. Due to irreversibility's a non-negligible auxiliary electric energy to overcome friction losses in the pipe work, fitting and heat exchangers is needed. In order to achieve high seasonal energy efficiency (SEER) the overall hydraulic power must be minimized and all pumps of the different hydraulic circuits must be designed to operate in Best Efficiency Point (BEP) under any load condition.

\subsection{Pump efficiency}

In general the efficiency of a centrifugal pump is defined as the ratio of the power exerted to the fluid in relation to the supplied electricity. This performance figure is not fixed for a given pump. Efficiency changes depend on discharge, operating head and size of the pump. While huge water pumps in power plants e.g. pumping hundreds of cubic meter reach high values up to $90 \%$, the overall efficiency of small pumps, as implemented in SHC-Systems, is less than $60 \%$. Due to improper hydraulic system design and inappropriate pump selection the overall electricity consumption of the solar-thermally driven sorption cooling and heating systems is sharply higher than essential. As a result the seasonal energy efficiency ratio SEER hangs considerable behind the expectations.

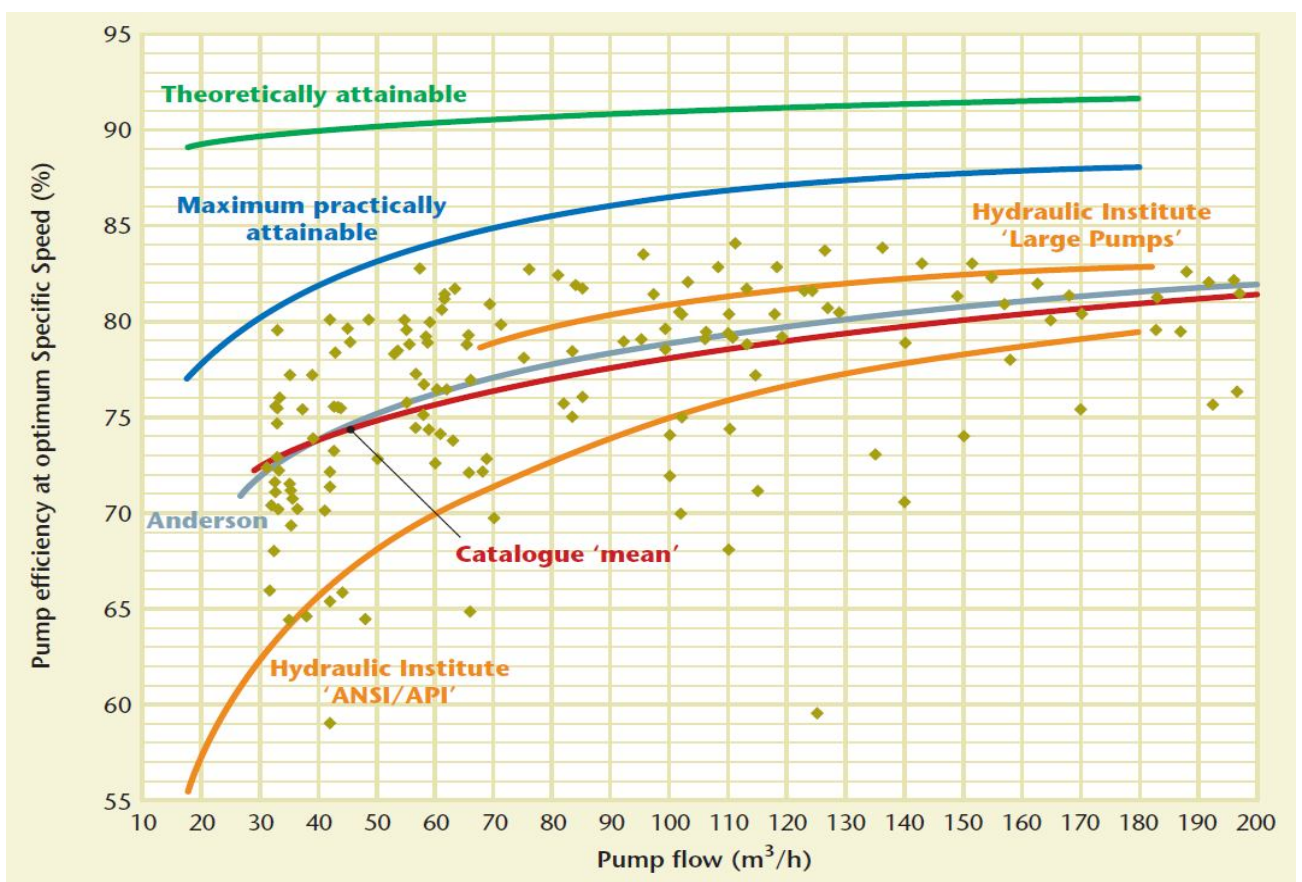

Figure 1: Pump efficiency at optimum specific speed for certain pump flows (Source: European Commission [1]) 


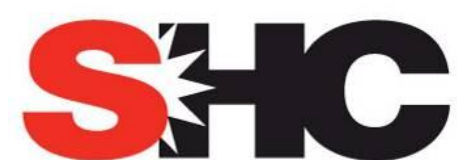

SOLAR HEATING \& COOLING PROGRAMME INTERNATIONAL ENERGY AGENCY

IEA SHC Task 48 / task48.iea-shc.org

\section{Task 48}

\subsection{Thermodynamic and hydraulic design criteria of solar driven chillers}

The following Table 1 shows a short overview about some market available hot water driven single stage Adsorption and Absorption chillers for solar Heating and Cooling Systems in the range from 8 to $100 \mathrm{~kW}$ chilled water capacity. Depending on the overall thermal Coefficient of Performance and the temperature difference between inlet and outlet of the chilled water, cooling water and hot water circuit a certain volume flow of the heat carrier medium is needed. Due to friction losses in the internal heat exchangers the pressure drop is not negligible and requires in some cases unacceptable high pumping effort and electricity consumption respectively.

Table 1: $\quad H y d r a u l i c$ circuit design criteria of solar driven chillers and calculation example

\begin{tabular}{|c|c|c|c|c|c|c|c|c|c|c|c|c|c|c|c|c|c|c|c|c|c|}
\hline \multirow[b]{2}{*}{ Manufacture } & \multirow[b]{2}{*}{ Type } & \multirow[b]{2}{*}{ Process } & \multirow[b]{2}{*}{ Capacity } & \multirow[b]{2}{*}{ Heat } & \multirow[b]{2}{*}{$\begin{array}{c}\mathrm{COP} \\
\text { thermal }\end{array}$} & \multicolumn{4}{|c|}{ Driving heat circuit } & \multicolumn{4}{|c|}{ Reject heat circuit } & \multicolumn{4}{|c|}{ chilled water circuit } & \multirow[b]{2}{*}{$\begin{array}{c}\text { Hydraulic } \\
\text { work }\end{array}$} & \multirow{2}{*}{\begin{tabular}{|c|} 
eta $40 \%$ \\
$\begin{array}{c}\text { min. } \\
\text { Electricity } \\
\text { for pumps }\end{array}$ \\
\end{tabular}} & \multirow[b]{2}{*}{$\begin{array}{l}\text { Electricity } \\
\text { internal }\end{array}$} & \multirow[b]{2}{*}{\begin{tabular}{|c|} 
EER \\
chiller
\end{tabular}} \\
\hline & & & & & & INLET & OUTLET & FLOW & $\begin{array}{c}\text { Pressure } \\
\text { drop }\end{array}$ & INLET & OUTLET & FLow & $\begin{array}{c}\text { Pressure } \\
\text { drop }\end{array}$ & INLET & OUTLET & FLOW & $\begin{array}{c}\text { Pressure } \\
\text { drop }\end{array}$ & & & & \\
\hline \multirow{5}{*}{\begin{tabular}{|l|} 
INVENSOR \\
\end{tabular}} & & & $\mathrm{kW}$ & $\mathrm{kW}$ & & $\begin{array}{ll}{ }^{\circ} \mathrm{C} \\
\end{array}$ & ${ }^{\circ} \mathrm{C}$ & $\mathrm{m}^{3 / \mathrm{h}}$ & mbar & ${ }^{\circ} \mathrm{C}$ & ${ }^{\circ} \mathrm{C}$ & $\mathrm{m}^{3 / h}$ & mbar & ${ }^{\circ} \mathrm{C}$ & ${ }^{\circ} \mathrm{C}$ & $\mathrm{m}^{3 / \mathrm{h}}$ & $\mathrm{mbar}$ & & & & \\
\hline & HTC18vario & Adsorption Zeolite/H2O & 18 & 34.6 & 0.52 & 85 & 76.5 & 3.6 & 310 & 27 & 34.5 & 6 & 290 & 18 & 14 & 3.9 & 300 & 111.8 & 279.6 & 20.0 & 60.1 \\
\hline & HTC18plus & Adsorption Zeolite/H2O & 18 & 34.6 & 0.52 & & & & pump incl. & & & & pump incl. & & & & pump incl. & & & & 36.4 \\
\hline & LTC10vario & Adsorption Zeolite/H2O & 10 & 16.7 & 0.60 & 72 & 66 & 2.5 & $5 \quad 220$ & 27 & 31.5 & 5.1 & 260 & 18 & 15 & 2.9 & 170 & 65.8 & 164.5 & 20.0 & 54.2 \\
\hline & LTC10plus & \begin{tabular}{|l|} 
Adsorption Zeolite/H2O \\
\end{tabular} & $\frac{10}{10}$ & 16.7 & 0.60 & $\frac{72}{72}$ & 66 & $\frac{2.5}{2.5}$ & 5 pump incl. & $\frac{17}{27}$ & $\frac{31.5}{31.5}$ & $\frac{1.1 \mathrm{R}}{5.45}$ & pump incl. & 18 & $\frac{15}{15}$ & & pump incl. & & & 395.0 & 25.3 \\
\hline \multirow{2}{*}{ SORTECH } & ACS15 & Adsorption silicagel/H2C & 15 & 26 & 0.58 & & $7 \mathrm{~K}$ & 3.2 & 260 & & $5 \mathrm{~K}$ & 7 & 440 & & $3 \mathrm{~K}$ & 4 & 500 & 164.2 & 410.6 & 14 & 35.3 \\
\hline & ACS08 & Adsorption silicagel/H2C & 8 & & "\#DIV/O! & & $7 \mathrm{~K}$ & 1.6 & 230 & & $5 \mathrm{~K}$ & 3.7 & 350 & & $3 \mathrm{~K}$ & 2 & 300 & 62.9 & 157.2 & 7 & 48.7 \\
\hline \multicolumn{2}{|c|}{ MITSUBISHI PAQSOA } & & 9.8 & 21.8 & 0.45 & 70 & 65.1 & 3.84 & 275 & 32 & 37.2 & 7.62 & 698 & 16 & 11 & 1.69 & 423 & 196.9 & 492.3 & 36 & 18.5 \\
\hline \multirow[t]{2}{*}{ AGO } & 100 & Absorption $\mathrm{H} 2 \mathrm{O} / \mathrm{NH} 3$ & 100 & 217 & 0.46 & 105 & 82 & & & 25 & 30 & & & 1 & -5 & & & & & 5570 & 18.0 \\
\hline & & Absorption $\mathrm{H} 2 \mathrm{O} / \mathrm{NH} 3$ & 50 & 109 & 0.46 & 105 & 82 & & & 25 & 30 & & & 1 & -5 & & & & & 4190 & 11.9 \\
\hline \multirow[t]{4}{*}{ EAW } & Wegracal SE 80 & Absorption LiBr/H2O & 83 & 111 & 0.75 & 86 & 71 & 6.4 & 70 & 27 & 32 & 33.4 & 400 & 15 & 9 & 12 & 70 & 4069 & 10172 & 3400 & $188 \mathrm{~F}>\mathrm{C}$ \\
\hline & Wegracal SE 50 & Absorption LiBr/H2O & 54 & 72 & 0.75 & 86 & 71 & 4.1 & 50 & 27 & 32 & $\frac{22}{22}$ & 450 & 15 & 9 & 7.7 & 65 & 294.6 & 736.5 & 3400 & 15.9 \\
\hline & Wegracal SE 30 & Absorption $\mathrm{LiBr} / \mathrm{H} 2 \mathrm{O}$ & 30 & 40 & 0.75 & 90 & 80 & 3.5 & 400 & 30 & 35 & 12 & 500 & 17 & 11 & 4.3 & 400 & 253.3 & 633.3 & 500 & 26.5 \\
\hline & Wegracal SE 15 & Absorption LiBr/H2O & 15 & 21 & 0.71 & 90 & 80 & 1.8 & 400 & 30 & 35 & 5 & 900 & 17 & 11 & 1.9 & 400 & 166.1 & 415.3 & 300 & 21.0 \\
\hline \multirow{3}{*}{ PINK } & PC19 Minus & Absorption $\mathrm{H} 2 \mathrm{O} / \mathrm{NH} 3$ & 12.3 & 26 & $0.47>-2>$ & 95 & 88 & 3.2 & 640 & 24 & 30 & 5.5 & 270 & 0 & -3 & 3.5 & 120 & 109.8 & 274.5 & 450 & $1700-2=0$ \\
\hline & PC19 Fan-coils & Absorptio & 18.6 & 30 & 0.62 & 85 & 78 & 3.6 & 680 & $\frac{24}{24}$ & 30 & 6.9 & 440 & 12 & 6 & 2.7 & 65 & 157.2 & 393.0 & 450 & 5.5 \\
\hline & PC19 act.ceiling & Absorption $\mathrm{H} 2 \mathrm{O} / \mathrm{NH} 3$ & 19.5 & 27 & 0.72 & 75 & 68 & 3.3 & 650 & 24 & $\frac{0}{30}$ & 6.7 & 410 & $\frac{14}{18}$ & $\frac{0}{15}$ & 5.6 & 280 & 179.4 & 448.6 & 450 & $\frac{3.7}{21.7}$ \\
\hline HUIN & $R X Z-58$ & Absorption LiBr/H2O & 58 & 82 & 0.71 & 90 & 85 & 14.3 & 500 & 30 & & 25 & 500 & 15 & 10 & 10 & 400 & 656.9 & 1642.4 & 300 & 29.9 \\
\hline & $\mathrm{RXZ}-35$ & $\begin{array}{l}\text { Absorption } \mathrm{LiBr} / \mathrm{H} 2 \mathrm{O} \\
\end{array}$ & 35 & 49 & 0.71 & 90 & 85 & 8.6 & 400 & 30 & & 15 & 400 & $\frac{5}{15}$ & 10 & 6 & 300 & 312.2 & 780.6 & 300 & 32.4 \\
\hline & $\mathrm{RXZ}-23$ & Absorption LiBr/H2O & 23 & 33 & 0.70 & 90 & 85 & 5.8 & 400 & 30 & & 10 & 400 & 15 & 10 & 4 & 300 & 208.9 & 522.2 & 300 & 28.0 \\
\hline & $R X Z-11$ & Absorption LiBr/H2O & 11 & 16.5 & 0.67 & 90 & 85 & 2.9 & 800 & 30 & & 5 & 500 & 15 & 10 & 2 & 600 & 167.2 & 418.1 & 150 & 19.4 \\
\hline THERMAX & LT-2 & Absorption LiBr/H2O & 70 & 100 & 0.70 & 90.6 & 85 & 15.7 & 200 & 29.4 & 36.7 & 20 & 300 & 12.2 & 6.7 & 11 & 590 & 434.2 & 1085.4 & 600 & 41.5 \\
\hline & LT-1 & Absorption LiBr/H2O & 35 & 50 & 0.70 & 90.6 & 85 & 7.8 & 120 & 29.4 & 36.8 & 10 & 120 & 12.2 & 6.7 & 5.5 & 680 & 163.2 & 408.1 & 600 & 34.7 \\
\hline SAKURA & $\mathrm{SHLO} \quad \mathrm{C}$ & Absorotic & 35.2 & 49.3 & 0.714 & 88 & 83 & 8.4 & 60 & 31 & 36.5 & 13.13 & 300 & 13 & 8 & 6 & 270 & 168.4 & 4210 & 180 & 58.6 \\
\hline & SHLO08 & 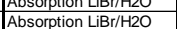 & $\frac{35.2}{26.1}$ & $\begin{array}{l}49.3 \\
36.45 \\
\end{array}$ & 0.716 & 88 & 83 & $\begin{array}{l}8.4 \\
6.7 \\
\end{array}$ & 60 & 31 & $\frac{36.5}{36.5}$ & $\begin{array}{l}13.13 \\
10.51 \\
\end{array}$ & 320 & $\frac{13}{13}$ & $\frac{8}{8}$ & $\begin{array}{r}6 \\
4.8\end{array}$ & $\frac{210}{250}$ & 108.4 & $\frac{42.0}{344.8}$ & 180 & $\frac{58.6}{49.7}$ \\
\hline & SHLO05 & Absorption LiBr/H2O & 17.6 & 24.65 & 0.714 & 88 & 83 & 4.2 & 30 & 31 & 36.5 & 6.57 & 140 & 13 & 8 & 3 & 260 & 50.7 & 126.8 & 100 & 77.6 \\
\hline & SHLO03 & Absorption LiBr/H2O & 10.5 & 14.58 & 0.72 & 88 & 83 & 2.5 & 30 & 31 & 36.5 & 3.94 & 130 & 13 & 8 & 1.8 & 210 & 26.8 & 67.0 & 100 & 62.9 \\
\hline Dummy & Test11 & not defin & 10 & 16.67 & 0.6 & 90 & 85 & 2871 & 1060 & 37 & 42 & 4.593 & 1050 & 13 & 10 & 2871 & 550 & 2624 & 6559 & 100 & $132+2+3$ \\
\hline \begin{tabular}{|l|l} 
Dummy \\
\end{tabular} & Test22 & not defined & 10 & 16.67 & 0.6 & 90 & 85 & 2.871 & $\begin{array}{l}1060 \\
1060\end{array}$ & 37 & $\frac{42}{45}$ & 2.871 & $\frac{1000}{420}$ & $\frac{13}{13}$ & 10 & 2.871 & 550 & $\frac{20<.4}{161.9}$ & $\begin{array}{l}050.9 \\
0047\end{array}$ & 100 & 19.8 \\
\hline Dumm & Test33 & not defil & 10 & 16.67 & 0.6 & 90 & 85 & 2.871 & 1060 & 37 & 45 & 2.871 & 420 & 15 & 10 & 1.722 & 200 & 127.6 & & 100 & 23.9 \\
\hline Dummy & Test44 & not defined & 10 & 16.67 & 0.6 & 90 & 80 & 1.435 & 260 & 37 & 45 & 2.871 & 420 & 15 & 10 & 1.722 & 200 & 53.4 & 133.6 & 100 & 42.8 \\
\hline Dummy & Test55 & not defined & 10 & 12.5 & 0.8 & 90 & 80 & 1.077 & 150 & 37 & 45 & 2.422 & 300 & 15 & 10 & 1.722 & 200 & 34.2 & 85.6 & 100 & 53.9 \\
\hline YAZAKI & WFC-SC30 & Absorption LiBr/H2O & 105 & 151.2 & 0.69 & 88 & 83 & 35.9 & 604 & 31 & 35 & 55.1 & 464 & 12.5 & 7 & 16.5 & 701 & 16338 & 40845 & 310 & 239 \\
\hline FALARI & WFC-SC20 & Absorption LiBr//H2O & $\frac{05}{70}$ & $\frac{15.2}{100.8}$ & $\frac{0.09}{0.69}$ & $\frac{60}{88}$ & $\frac{63}{83}$ & $\begin{array}{r}37.5 \\
17.28 \\
\end{array}$ & $\begin{array}{ll}004 \\
464 \\
\end{array}$ & $\frac{31}{31}$ & $\frac{35}{35}$ & 36.7 & 年643 & $\frac{12.5}{12.5}$ & $\frac{1}{7}$ & $\frac{1.5}{11}$ & $\frac{101}{658}$ & $\frac{1033.0}{885.6}$ & $\frac{4004.5}{2214.0}$ & $\frac{310}{260}$ & $\frac{25.5}{28.3}$ \\
\hline & WFC-SC10 & Absorpt & 35 & 50.2 & 0.70 & 88 & 83 & 1,20 & 904 & 31 & 35 & 18.4 & 853 & 12.5 & 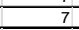 & 5.5 & 561 & 738.6 & 1846.6 & 210 & 17.0 \\
\hline & WFC-SC05 & Absorption LiBr/H2O & 17.5 & 25.1 & $\frac{0.70}{0.70}$ & 88 & $\frac{60}{83}$ & $\frac{0.04}{4.32}$ & 770 & 31 & 35 & $\frac{1.4}{8.2}$ & $\frac{303}{383}$ & 12.5 & $\frac{1}{7}$ & $\frac{0.5}{2.77}$ & 526 & 220.1 & $\frac{1060.6}{550.3}$ & $\frac{210}{48}$ & 29.3 \\
\hline
\end{tabular}

On the basis of manufacturer data the unavoidable hydraulic power in the three main circuits to overcome the friction losses in the heat exchangers is calculated to estimate the minimum overall electricity consumption for pumping assuming a pump efficiency of $40 \%$. Taking account of the internal electricity consumption of the chiller (control, refrigerant/sorbens pump etc.) a maximum possible EER for the chiller solely, neglecting the auxiliary energy consumption for solar collector circuit and reject heat dissipation, can be calculated.

The ratio between chilled water capacity and electricity consumption vary between 11.9 and 77.6. As a result the hydraulic design requirements of some market available chillers impede good seasonal performance. By way of illustration a notional chiller manufacturer named dummy offers the same 


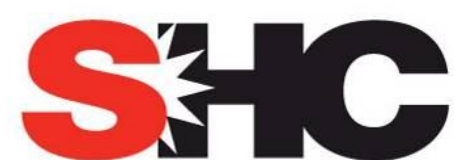

SOLAR HEATING \& COOLING PROGRAMME INTERNATIONAL ENERGY AGENCY

IEA SHC Task 48 / task48.iea-shc.org

\section{Task 48}

machine for different operational conditions. Chiller Test11 requires very small temperature differences between Inlet and Outlet in the hydraulic circuits whereby the necessary flow of the heat carrier medium and the resulting pressure drop is rather high. By stepwise increasing the temperature differences in the hydraulic circuits a significant increase in EER is obtained. Test 55 shows a very good thermo-hydraulic design with promising temperature levels for widespread applications under European climatic conditions. Compared to Test44 the additional improved thermal COP leads to further significant improvement in EER, due to reduced energy demand and heat rejection effort.

Beside overall pump efficiency and thermal design of the chiller another important aspect is given by the adaptability to part load conditions. Most of the SHC-installations operate mainly under part load conditions depending on climatic conditions and load profile of the building. If there's no flow adaption by adjusting pump speed applied, the overall auxiliary electricity energy consumption remains constant. E.g. if the chilled water capacity of Test55 chiller is reduced by $50 \%$ to $5 \mathrm{~kW}$, without adjusting the flows of the heat carrier medium, the EER drops from 54 to 27 accordingly. On the other hand a dynamic adaption of the pump speed related to the current load of the chiller allows theoretically a cubical reduction of auxiliary energy consumption based on the affinity laws.

The way things are an overall SEER for well-designed small scale solar cooling systems of 20 seems to be feasible. However, currently many manufacturers mainly focus on cheap chillers than good seasonal system performance. As the thermodynamic and hydraulic design criteria of the chiller defines the capacities, temperature levels and/or heat transfer medium flows in the entire solar cooling system the following criteria's should be taken into account:

$>$ Possibility of heat transfer medium flow reduction in the chilled water, cooling water and driving heat circuit to reduce the electricity consumption in part load conditions (some chillers have installed flow detectors at the entrance of each component which shut down the machine automatically at e.g. $80 \%$ of the nominal flow. The same difficulty may occur by using open wet cooling towers for heat rejection. Since the cooling water is sprayed directly into the column, this nozzles often require a certain minimal heat carrier medium flow and pressure to ensure a satisfying operation of the wet cooling tower. At any case if not mentioned in the manual

> High thermal COP in a wide capacity range to diminish the driving heat and reject heat flow to and from the machine. This is a crucial aspect as the thermal COP influences both the hydraulic design of cooling water and driving heat circuit as well as the capacity of the solar collector field and heat rejection device. The higher the thermal COP the less driving heat and therefore pumping effort in the collector area is necessary. As less driving heat is required to produce the same amount of chilled water the thermal discharge a ventilation effort is reduced accordingly.

$>$ High temperature spread in the main hydraulic circuits reduces significantly the heat transfer medium flow per thermal unit and the required piping diameters.

$>$ High reject heat temperatures facilitate the heat dissipation to the ambient and allow for dry heat rejection as well. By avoiding a wet or hybrid cooling tower and its associated electricity consuming water make-up and preparation system (which is often incorrectly not taken into account) a further reduction of auxiliaries and fresh-water consumption is achieved.

$>$ Low pressure drop in the heat exchangers of Evaporator, Condenser, Ad-/Absorber and Desorber. In this context a very well balanced compromise between sufficient heat transfer coefficient and 


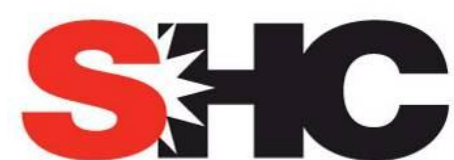

SOLAR HEATING \& COOLING PROGRAMME INTERNATIONAL ENERGY AGENCY

IEA SHC Task 48 / task48.iea-shc.org

\section{Task 48}

pressure drop as well as turbulent and laminar flow through the heat exchangers has to be targeted.

- Low internal electricity consumption (reduces the available electricity consumption for pumping and heat dissipation). While Adsorption machines are at an advantage over the absorption machines due to their discontinuous process without any internal refrigeration or solution pump, the overall performance suffers under the far smaller thermal COP.

Another significant effect on EER and system performance constitutes the heat rejection to the ambient by dry, wet or hybrid cooling towers. This difficulty context is described in Working group A3. 


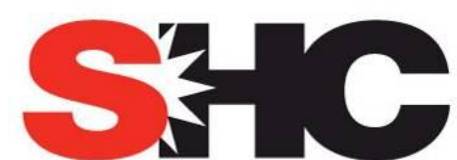

SOLAR HEATING \& COOLING PROGRAMME INTERNATIONAL ENERGY AGENCY

IEA SHC Task 48 / task48.iea-shc.org

\section{Task 48}

\subsection{Hydraulic circuits and auxiliary electricity consumption in SHC-systems}

There is a multitude of design and performance assessment tools as well as graphical circuit diagrams to describe the general arrangement and connection of the main components in solar heating and cooling systems. The source/sink Approach developed in Task44 and the Monitoring Procedure of Task 38 e.g. outline energy flows between the components without any information about hydraulics and ICA equipment while the "Generic System schemes" [2] of Task 38 condenses technical circuit diagrams based on ISO 1219-2:2012 to sub systems with reduced piping and instrumentation.
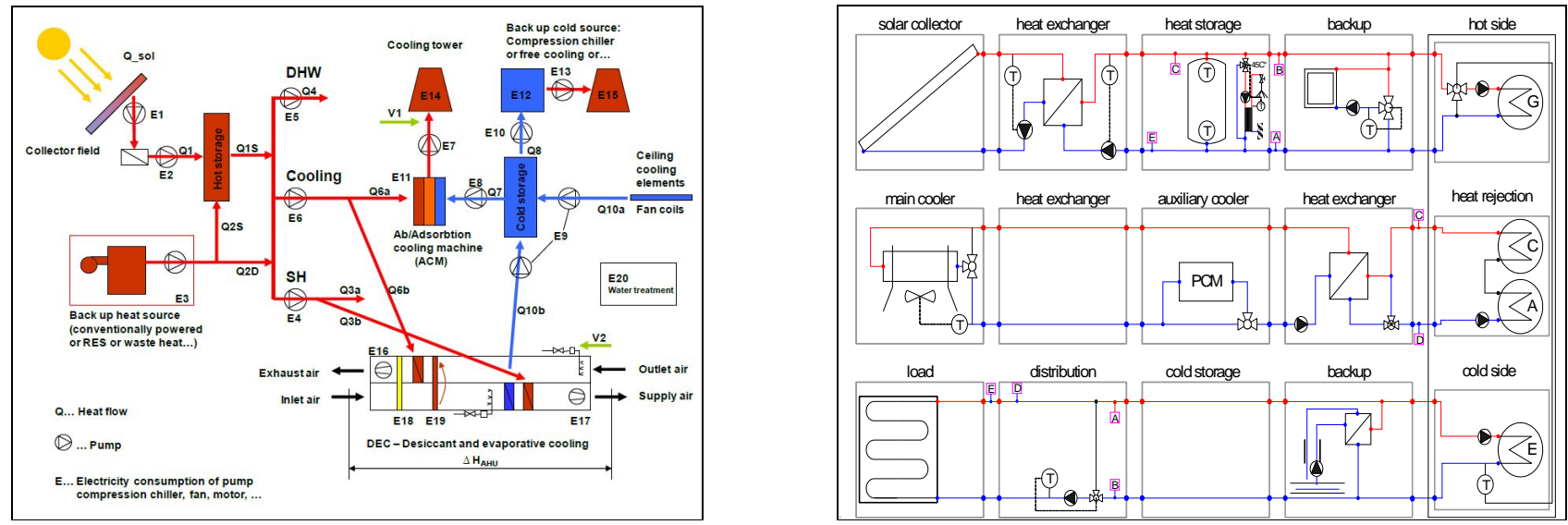

Figure 2: $\quad$ Task38 monitoring procedure (left) and generic system schemes (right)

In general the components of a solar cooling system can be classified into the following sub systems in order to identify their portion on the overall electricity consumption without excessive measuring equipment and detailed analysis of the hydraulic components. The ratio between transferred thermal unit from a heat source to a heat sink and the therefore required electricity is defined as Auxiliary Energy Consumption Ratio (AECR) and allows a direct comparison and validation of the hydraulic efficiency among different installations. The AECR includes both hydraulic circuit design and electrical efficiency of the pumps.

\section{Solar collector sub-system ( $\left.\mathrm{AECR}_{\text {Solar }}\right)$}

This hydraulic circuit connects the flat plate, evacuated tube or concentrating solar thermal collectors to a heat storage or directly to the Desorber of the chiller and is defined as follows.

$$
A E C R_{\text {Solar }}=\frac{Q_{\text {SolarHeat }}}{\sum_{i=1}^{n} P_{\text {SolarCollectorCircut }}}
$$

\section{Backup heat sub-system (AECR Backup $_{\text {) }}$}

This circuit includes additional back up heat sources e.g. fossil - biofuel boiler, district heating or any waste heat source feeding the heat storage or Desorber of the chiller. 


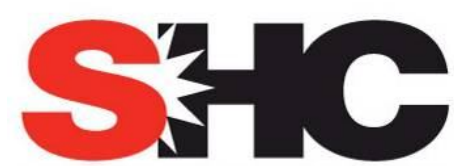

\section{Task 48}

$$
A E C R_{\text {Backup }}=\frac{Q_{\text {BackupHeat }}}{\sum_{i=1}^{n} P_{\text {Auxiliaries }}}
$$

Driving heat sub-system (AECR $)$

If a heat storage is installed between heat source and Desorber this additional hydraulic circuit is mandatory.

$$
A E C R_{D}=\frac{Q_{\text {Desorber }}}{\sum_{i=1}^{n} P_{\text {DrivingHeatCircuit }}}
$$

Heat rejection sub-system $\left(A E C R_{A C}\right)$

The reject heat from Condenser and Ab-/Adsorber has to be transferred to a heat sink or any other heat consumer.

$$
A E C R_{A C}=\frac{Q_{\text {Absorber } / \text { Condenser }}}{\sum_{i=1}^{n} P_{\text {CoolingWaterCircuit }}}
$$

Cooling tower sub-system (AECR $\left.\mathrm{Cooler}_{\mathrm{r}}\right)$

This subsystem includes the electricity consumption for water treatment, spraying, ventilation ASO.

$$
A E C R_{\text {Cooler }}=\frac{Q_{\text {Cooler }}}{\sum_{i=1}^{n} P_{\text {Fan }+ \text { Auxiliaries }}}
$$

Chilled water sub-system $\left(A E C R_{E}\right)$

The chilled water has to be transferred from the Evaporator of the Chiller to a cold storage or directly to the distribution system of the building and considers at least the hydraulic power to overcome the friction losses in the Evaporator.

$$
A E C R_{E}=\frac{Q_{\text {Evaporator }}}{\sum_{i=1}^{n} P_{\text {ChilledWaterCircuit }}}
$$

Chiller internal sub-system (AECR chiller $\left._{\text {r }}\right)$ 


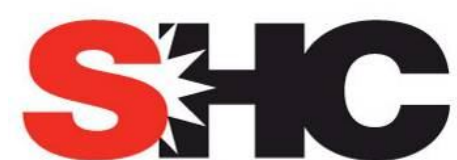

SOLAR HEATING \& COOLING PROGRAMME INTERNATIONAL ENERGY AGENCY

IEA SHC Task 48 / task48.iea-shc.org

\section{Task 48}

Depending on the chiller type more or less electricity is consumed in the machine itself to maintain the sorption process and vacuum.

$$
A E C R_{\text {chiller }}=\frac{Q_{\text {Evaporator }}}{\sum_{i=1}^{n} P_{\text {Auxiliaries }}}
$$

Based on this classification several solar cooling systems are analyzed concerning their electricity consumption in the hydraulic circuit, cooling tower and internal sorption process as well as its control and measuring system. The pie charts in Table 2 show the percentage of electricity consumption in the different sub-systems. Measuring results from several national Research projects (SolarCoolingMonitor / SolarCoolingOpt / Roccoco / SolarRück and Annex34 are listed.

Table 2: $\quad$ Proportion of electricity consumption in the different sub-systems

\section{Project: SOLID Coolcabin}

Location: Graz, Austria

Type: $\quad 17.5 \mathrm{~kW} \mathrm{LiBr/Water} \mathrm{Absorption} \mathrm{chiller}$

Brand: Yazaki

SEER: $\quad \sim 4$

Project: $\quad$ MA34

Location: Vienna, Austria

Type: $\quad 7.5 \mathrm{~kW}$ Silicagel/Water Adsorption chiller

Brand: Sortech

SEER: $\quad \sim 6$

\section{Project: $\quad$ BH Rohrbach}

Location: Rohrbach, Austria

Type: $\quad 30 \mathrm{~kW} \mathrm{LiBr/Water} \mathrm{Absorption} \mathrm{chiller}$

Brand: $\quad$ EAW

SEER: $\quad \sim 4,2$
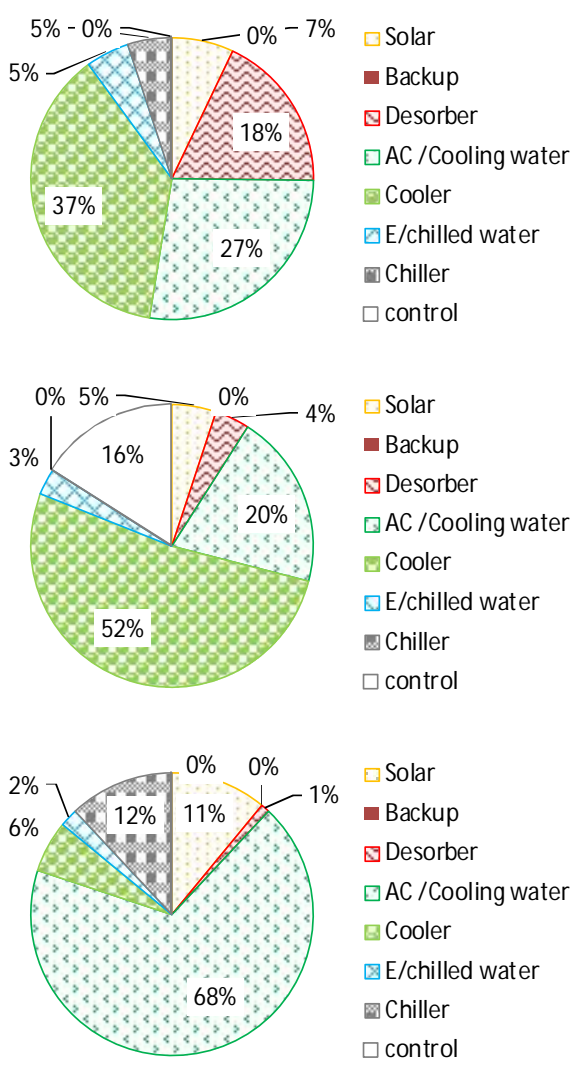


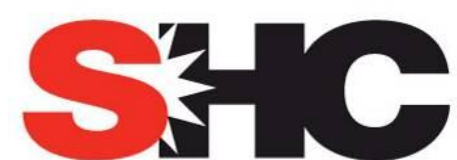

SOLAR HEATING \& COOLING PROGRAMME INTERNATIONAL ENERGY AGENCY

IEA SHC Task 48 / task48.iea-shc.org

\section{Task 48}

\section{Project: $\quad$ Sun Master / Xolar}

Location: Rohrbach, Austria

Type: $\quad 80 \mathrm{~kW} \mathrm{LiBr/Water} \mathrm{Absorption} \mathrm{chiller}$

Brand: $\quad$ EAW

SEER: $\quad \sim 6,7$

\section{Project: Gasokol}

Location: Saxen, Austria

Type: $\quad 30 \mathrm{~kW} \mathrm{LiBr/Water} \mathrm{Absorption} \mathrm{chiller}$

Brand: $\quad$ EAW

SEER: $\quad \sim 4,5$

\section{Project: Feistritzwerke}

Location: Gleisdorf, Austria

Type: $\quad 19$ kW NH3/Water Absorption chiller

Brand: PINK

SEER: $\quad \sim 5$

\section{Project: $\quad$ Caixa Geral de Depositos (CGD)}

Location: Lisbon, Portugal

Type: $\quad 545 \mathrm{~kW} \mathrm{LiBr} /$ Water Absorption chiller

Brand: BINGSHAN

SEER: $\quad \sim 5$

\section{Project: SolarHeatCool+PCM}

Location: Garching, Germany

Type: $\quad 10 \mathrm{~kW} \mathrm{LiBr/Water} \mathrm{Absorption} \mathrm{chiller}$

Brand: $\quad$ SK Sonnenklima

SEER: $\quad \sim 11$
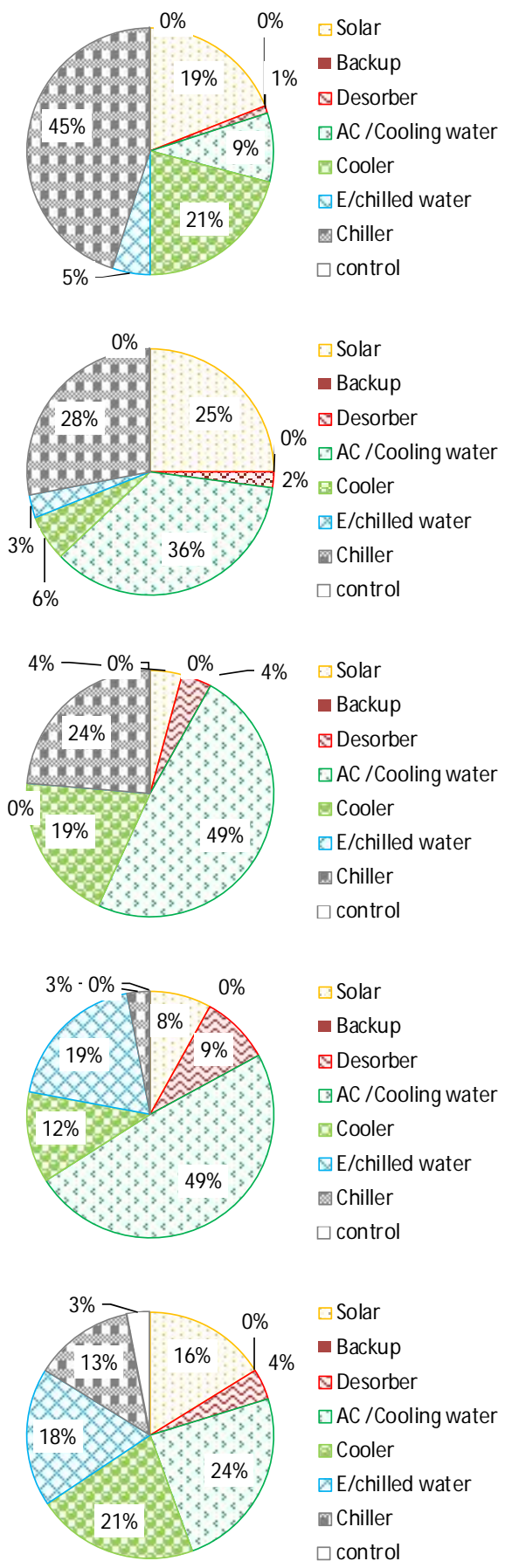

\section{Conclusion:}




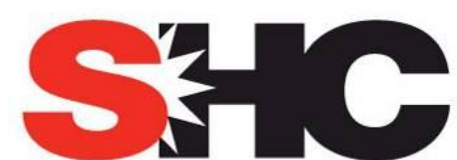

SOLAR HEATING \& COOLING PROGRAMME INTERNATIONAL ENERGY AGENCY

IEA SHC Task 48 / task48.iea-shc.org

\section{Task 48}

In most of the SHC-systems the electricity consumption of the heat dissipation system is dominating! More than $50 \%$ of the auxiliary energy is consumed by the cooling water pumps, fans and water make-up and preparation device. In general these Pie diagramms show best saving options for the evaluated systems and preferred application of speed controlled pumps. But on the other hand a direct comparison of system designs among different SHC installations is only possible with AECR values.

Figure 3 shows some selected solar cooling installations with either absorption or adsorption technology in a chilled water capacity range starting from $7.5 \mathrm{kw}$ up to about $1.5 \mathrm{MW}$. Most of the installations show a good ratio between transferred heat in the hydraulic circuits between solar collector array and buffertank (AECR_Solar) as well as subsequent heat supply to the chiller (AECR_D).

Due to either huge heat quantity and/or small temperature difference the high specific auxiliary energy consumption in the chilled and cooling water circuit requires a proper and efficient subsystem design.
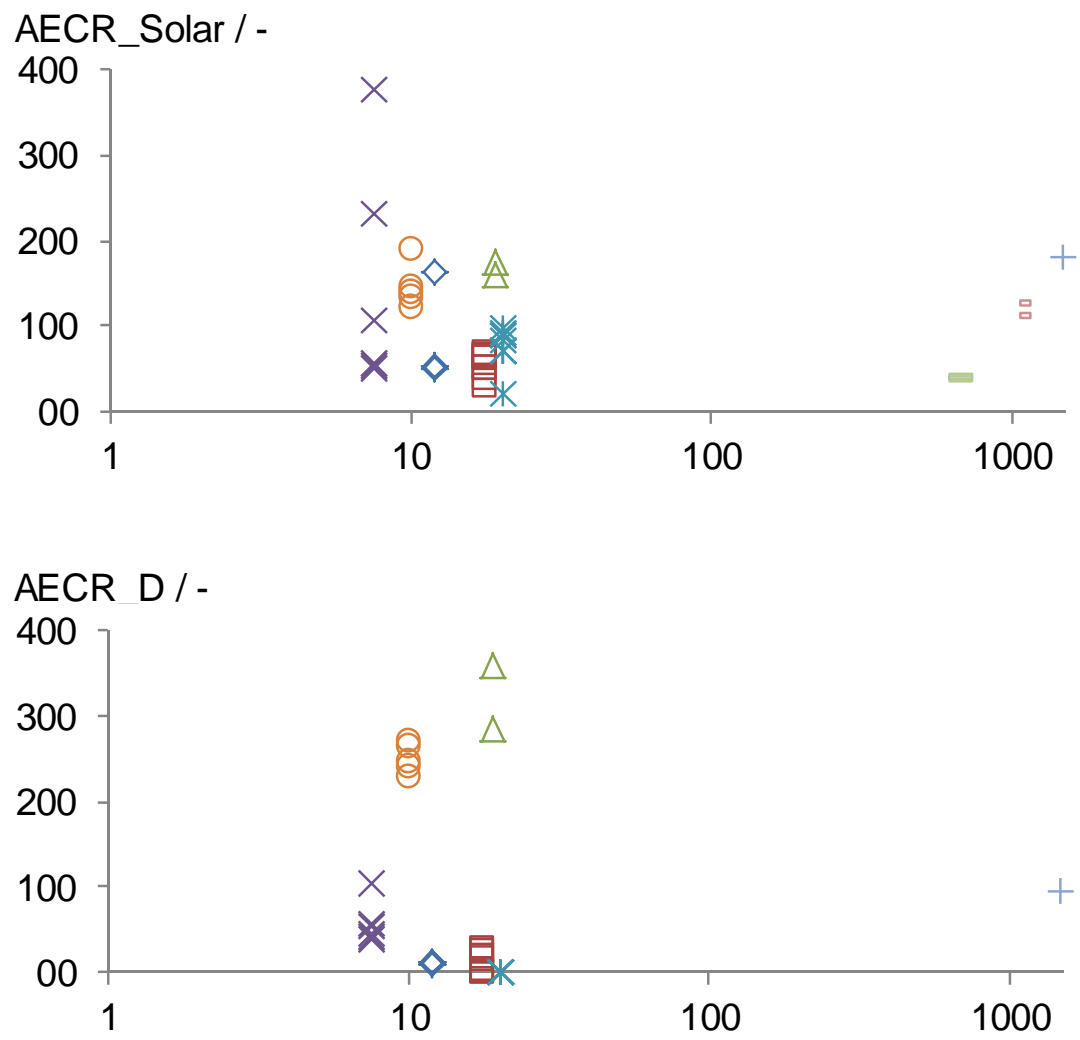

$\diamond$ Gröbming 12kW (monthly)

$\square$ SOLID 17.5 (monthly)

$\triangle$ Feistritz $19 \mathrm{~kW}$ (monthly)

XISE 7.5kW (monthly)

*Butzbach 2x10kW (monthly)

OZAE $10 \mathrm{~kW}$ (monthly)

+ UWC 1477kW (design)

-Festo 3x353 (yearly)

- Telekom 2x340kW (Yearly)

chilled water capacity / kW $\diamond$ Gröbming 12kW (monthly)

$\square$ SOLID 17.5 (monthly)

$\triangle$ Feistritz 19kW (monthly)

XISE $7.5 \mathrm{~kW}$ (monthly)

*Butzbach 2x10kW (monthly)

OZAE $10 \mathrm{~kW}$ (monthly)

+ UWC 1477kW (design)

-Festo 3x353 (yearly)

- Telekom 2x340kW (Yearly)

chilled water capacity / kW 


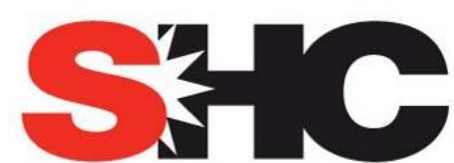

SOLAR HEATING \& COOLING PROGRAMME INTERNATIONAL ENERGY AGENCY

IEA SHC Task 48 / task48.iea-shc.org

\section{Task 48}
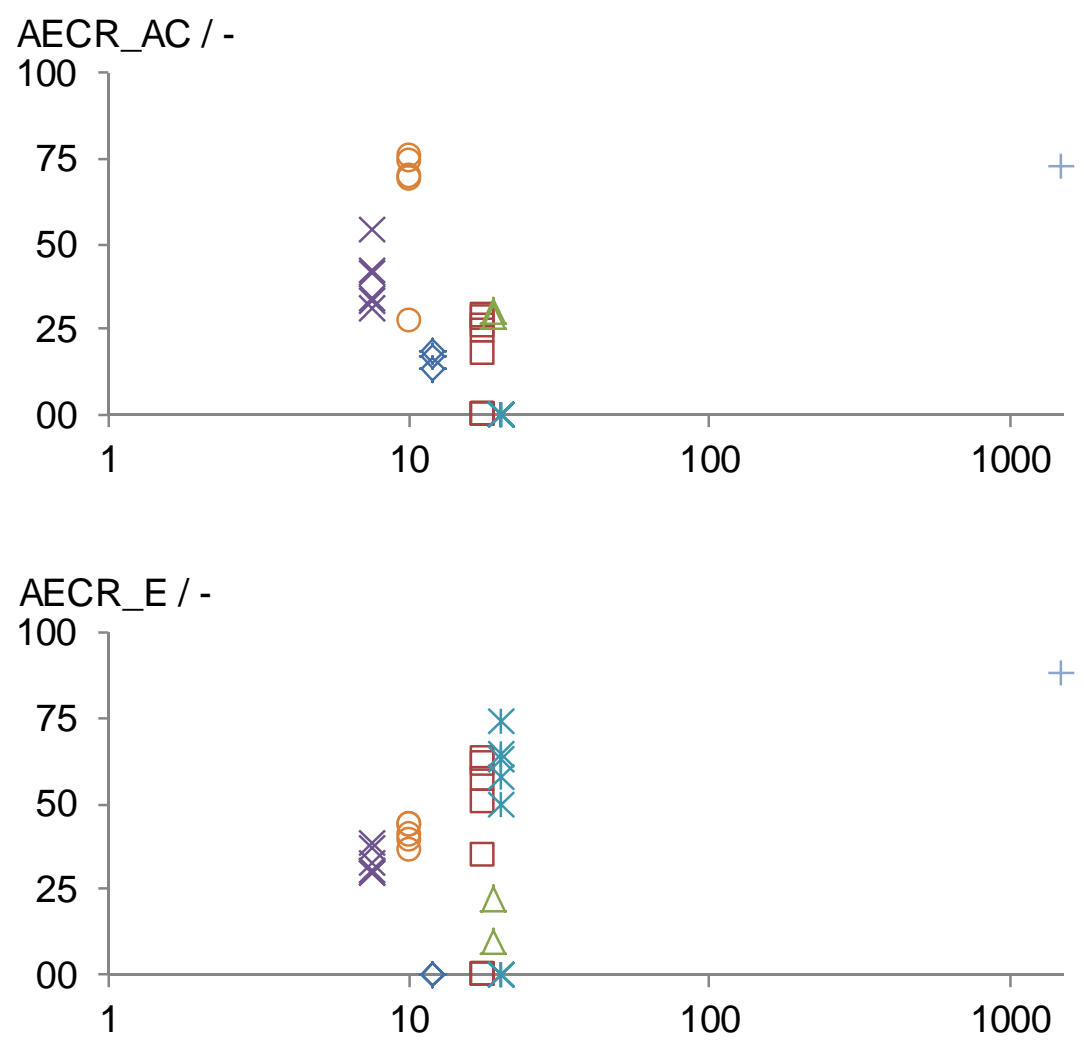

\author{
$\diamond$ Gröbming 12kW (monthly) \\ $\square$ SOLID 17.5 (monthly) \\ $\triangle$ Feistritz $19 \mathrm{~kW}$ (monthly) \\ XISE 7.5kW (monthly) \\ *Butzbach $2 \times 10 \mathrm{~kW}$ (monthly) \\ OZAE $10 \mathrm{~kW}$ (monthly) \\ +UWC 1477kW (design) \\ -Festo 3x353 (yearly) \\ - Telekom 2x340kW (Yearly) \\ chilled water capacitv / kW
}

$\diamond$ Gröbming $12 \mathrm{~kW}$ (monthly)

$\square$ SOLID 17.5 (monthly)

$\triangle$ Feistritz $19 \mathrm{~kW}$ (monthly)

$\times$ ISE $7.5 \mathrm{~kW}$ (monthly)

*Butzbach $2 \times 10 \mathrm{~kW}$ (monthly)

OZAE $10 \mathrm{~kW}$ (monthly)

+ UWC 1477kW (design)

-Festo 3x353 (yearly)

- Telekom 2x340kW (Yearly)

chilled water capacitv / kW

Figure 3: Auxiliary Energy Consumption Ratios in the main hydraulic circuits solar array, Heat supply to chiller, cooling and chilled water of some SHC-systems 


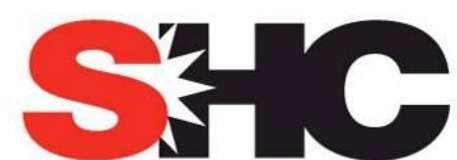

SOLAR HEATING \& COOLING PROGRAMME INTERNATIONAL ENERGY AGENCY

IEA SHC Task 48 / task48.iea-shc.org

\section{Task 48}

\subsection{Specific installation costs for pumps}

This section identifies the cost-sensitiveness and portion of costs regarding pumps in relation to the total investment of solar cooling applications.

In general, expenses for hydraulic circuits and installation account for one third of the cumulative costs as shown in Figure 5. Another third has to be spent on the solar thermal collectors. The chiller itself reflects in the budget about 15 to $20 \%$. Electrical wiring and control units cause minor overall costs of about $10 \%$. This investigation had been performed in the EU-Project ROCOCO [3] for medium cooling capacities between $70-180 \mathrm{~kW}$ and could be confirmed by several other projects as well.

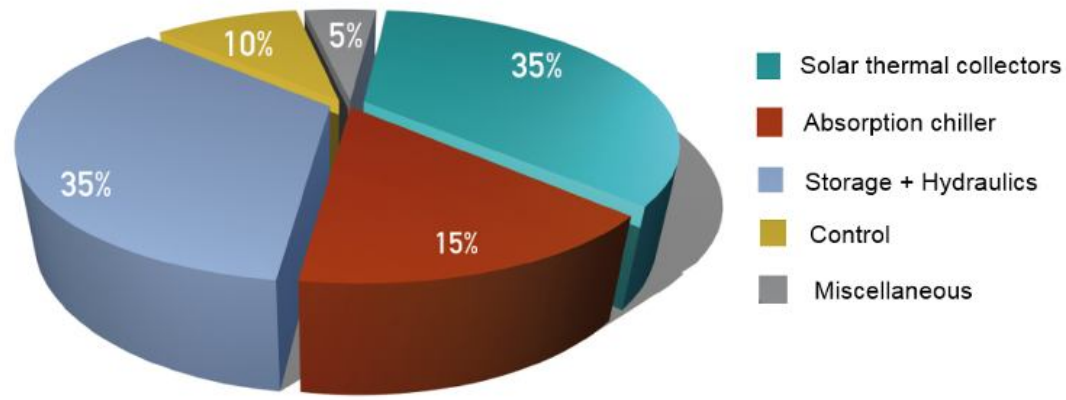

Figure 4: $\quad$ Characteristic cost distribution in SHC systems with absorption chillers.(Source: [3])

Although heat transfer fluid circuit installation contributes to the overall SHC system costs in a large part, the single investment for pumps itself account for less than $5 \%$ in general as shown exemplary in Figure 5 or described for another 5 thermal cooling installations by D. Schall, S. Hirzel [4].

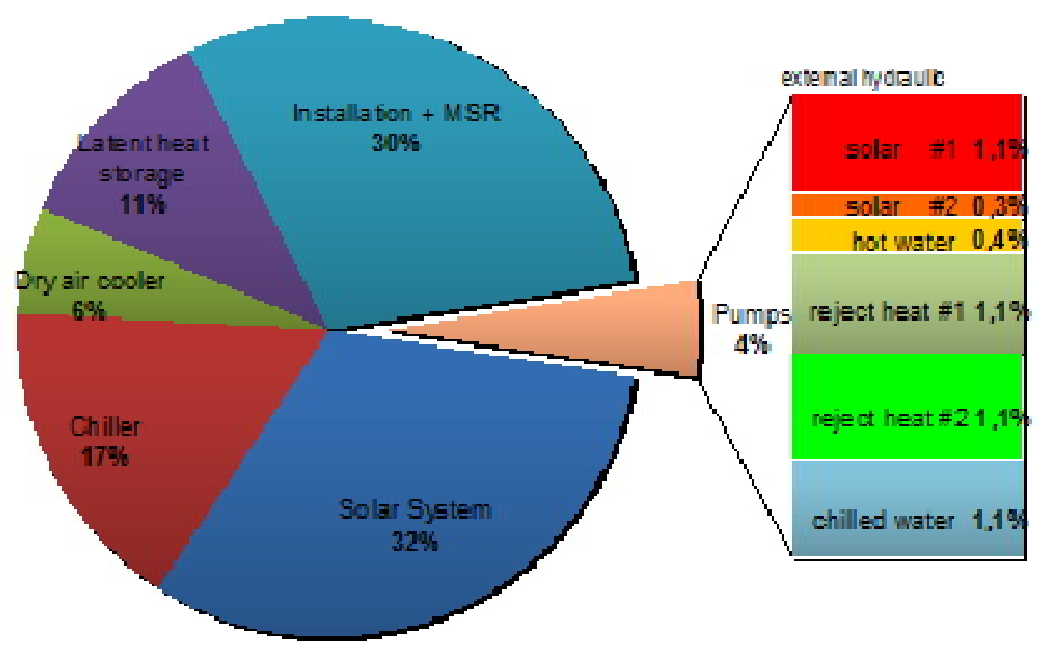

Figure 5: $\quad$ Investment costs in a $10 \mathrm{~kW}$ absorption cooling system with dry heat rejection 


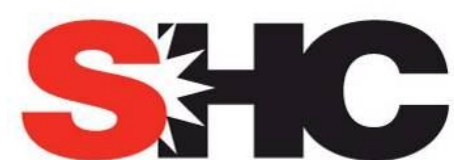

SOLAR HEATING \& COOLING PROGRAMME INTERNATIONAL ENERGY AGENCY

IEA SHC Task 48 / task48.iea-shc.org

\section{Task 48}

\section{Conclusion:}

A life cycle costs calculation of pumps comprises among other things costs for purchase, installation as well as commissioning, energy consumption during lifetime and maintenance. As prices, operation hours and energy costs vary significantly among SHC-systems and even countries; a comprehensive statement is therefore not possible. Even though investment costs of a variable speed high-efficiency pumps often are twice as high compared to a cheap but inefficient fixed speed pump the overall costs for pumps in SHC systems are rather small or often negligible. But adjusting pump speed to part load conditions has a high impact on system efficiency regarding EER. Nevertheless in most of the cases, especially in installation with high operational hours, the pay back is achieved through auxiliary energy savings in a reasonable period of time. 


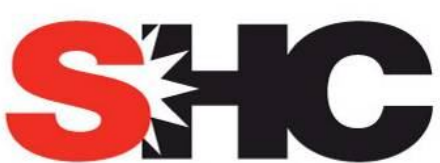

SOLAR HEATING \& COOLING PROGRAMME INTERNATIONAL ENERGY AGENCY

IEA SHC Task 48 / task48.iea-shc.org

\section{Task 48}

\section{Pump Efficiency - Theoretical -}

This chapter gives a short overview about the theory of rotodynamic pumps and crucial design criteria as well as international legislative regulations and shows some real operating points of pumps in solar cooling applications. Figure 6 shows the classification of hydraulic pumps. As almost exclusively kinetic centrifugal volute radial impeller pumps are applied in SHC-Systems this chapter focus only on this pump type.
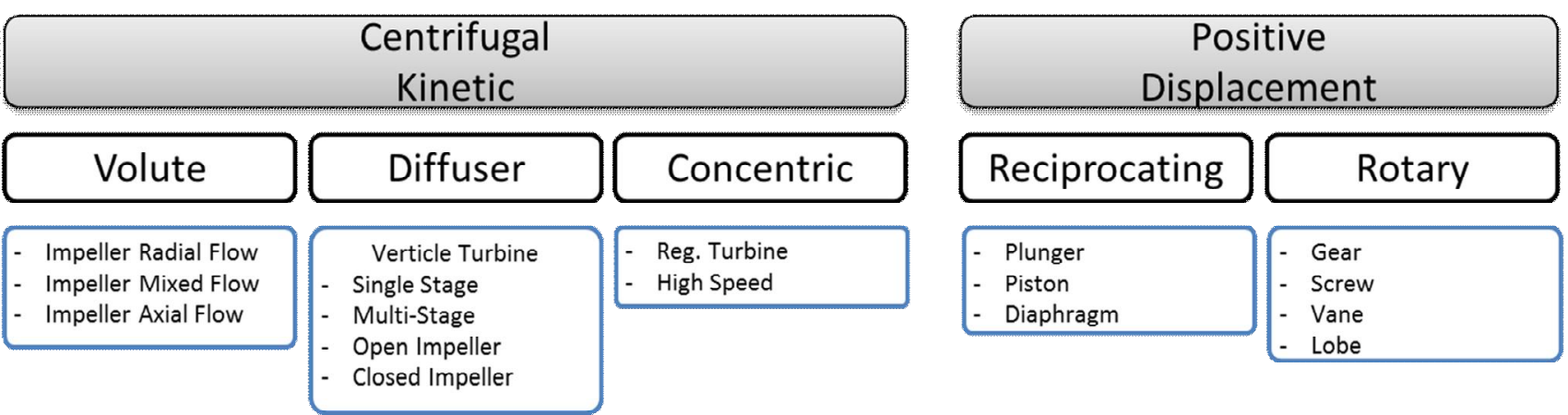

Figure 6: Classification of pump types

In recent years a high increase in the overall efficiency of roto-dynamic pumps had been obtained due to international regulations and standardization such as the EuP-Directive (Directive 2009/125/EC) of 2009, the Energy Efficiency Index EEl involving canned single circulator pumps with less than $2500 \mathrm{~W}$ electricity consumption and the new International Efficiency classes of motors (IE) concerning lowvoltage three phase asynchronous motors from $0.75 \mathrm{~kW}$ to $375 \mathrm{~kW}$. [5]

Table 3: $\quad$ Predominant rotodynamic pump types, canned and shafted, installed in SHC systems

\begin{tabular}{|c|c|}
\hline canned rotodynamic pumps & shafted rotodynamic pumps \\
\hline (only single stage) & single and multistage \\
\hline $\begin{array}{c}\text { Millions of units (2005: } 120 \text { million installed in } \\
\text { residential heating systems) }\end{array}$ & $\begin{array}{c}\text { Multiple thousands especially in industrial } \\
\text { processes }\end{array}$ \\
\hline up to $15 \mathrm{~m}$ head, max. volume $\sim 50 \mathrm{~m}^{3} / \mathrm{h}$ & "No limit" \\
\hline
\end{tabular}




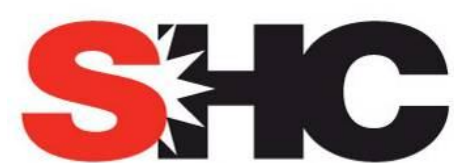

\section{Task 48}

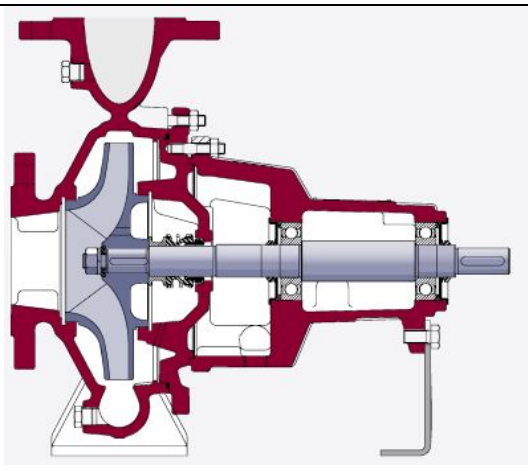

Figure 8: Sectional view of a shafted rotodynamic pump. Source: Pump handbook [6]
Figure 7: $\quad$ Sectional view of a canned rotodynamic pump. Source: Pump handbook [6]$$
\text { pump. Sou }
$$

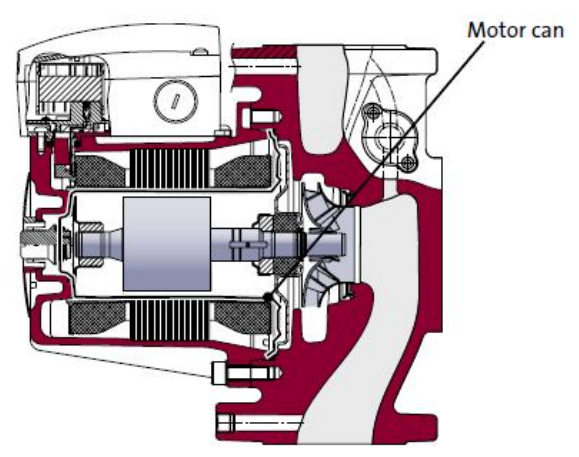

Centrifugal pumps perform work by manipulation the velocity of the fluid passing through the impeller of the pump from the inner diameter (ID) to the outer diameter (OD). In the following diffusor dynamic pressure of the fluid is converted into static pressure by flow cross-section expansion.

\section{The Affinity laws and their effect on part load conditions $[7,8,9]$}

The affinity laws describe the theoretical dependency of rotation speed, head and power consumption of rotary pumps for ideal, frictionless and incompressible flow. In good approximation they describe the real behavior of speed-controlled rotary pumps.

Equation 9 describes the proportion relation between flow $\mathrm{Q}$ and rotation speed $\mathrm{n}$ of the pump.

$$
\frac{Q_{2}}{Q_{1}}=\frac{n_{2}}{n_{1}}
$$

Linking equation 9 and 10 shows the quadratic relationship between flow and pump head $\mathrm{H}$ which is equal to the pressure drop in the hydraulic circuit.

$$
\frac{H_{2}}{H_{1}}=\left(\frac{n_{2}}{n_{1}}\right)^{2}
$$

Referred to the power consumption $\mathrm{P}$ of the pump a flow or rotation speed reduction has a cubical influence.

$$
\frac{P_{2}}{P_{1}}=\left(\frac{n_{2}}{n_{1}}\right)^{3}
$$




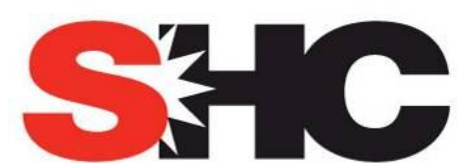

SOLAR HEATING \& COOLING PROGRAMME INTERNATIONAL ENERGY AGENCY

IEA SHC Task 48 / task48.iea-shc.org

\section{Task 48}

Furthermore the overall efficiency and power consumption of pumps is influenced by a lot of factors.

- The impeller velocity

- The impeller diameter (trim limited by $20 \%$ )

- The number of blades on the impeller

- The diameter of the eye of the impeller

- The thickness of the impeller

- The pitch of the blades

- Surface finish of internal surfaces

- Wear ring tolerance (tremendous effect on pumps with low specific speed)

- Mechanical losses (Bearings, seals, packings ...)

- Viscosity of the heat transfer medium (Head remains the same, but enhances power input)

As shown prior in Figure 1, current rotodynamic pumps feature excellent performance up to $80 \%$ and more in the high capacity range, but efficiency drops below $50 \%$ and less when smaller pumps have to be used.

In general, characteristic pump QH-curves are designed in accordance to ISO 9906 Rotodynamic pumps - Hydraulic performance acceptance tests - Grades 1,2 and3, in which tolerances are specified as following:

$\begin{array}{llcl}\text { Flow } & \mathrm{Q} & \pm 9 \% & \mathrm{~m}^{3} / \mathrm{h} \text { or } \mathrm{l} / \mathrm{s} \text { or } \mathrm{l} / \mathrm{min} \\ \text { Head } & \mathrm{H} & \pm 7 \% & \mathrm{~m} \\ \text { Electrical Power } & \mathrm{P}_{1} & \pm 9 \% & \mathrm{~W} \text { or kW } \\ \text { Efficiency } & \mathrm{n} & -7 \% & -\end{array}$

\section{QH-curve:}

This typical graph shows the characteristic QH-curve of a specific pump in terms of flow $Q_{1}$ and discharge head $\mathrm{H}_{1}$ in meter. Low flows allow for high discharge pressure. With decreasing pressure difference between inlet and outlet of the pump the flow increases while available head bottoms out.

The pump characteristic line represents one revolution speed. If a speed converter is applied this line slides down in parallel. A minimum revolution is required for canned pumps to ensure adequate motor cooling by the fluid flowing through the pump. In general a modulation rate of $1: 4$ in flow is available.

The system characteristic or pressure drop respectively increases quadratic starting at zero in case of a closed hydraulic system. The duty point, the match between pump and system characteristic should be designed next or slightly right to the Best Efficiency Point (BEP) of the rotodynamic pump. 


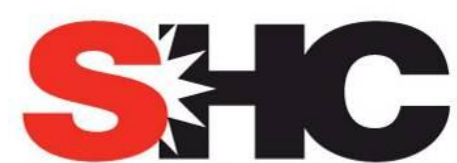

SOLAR HEATING \& COOLING PROGRAMME INTERNATIONAL ENERGY AGENCY

IEA SHC Task 48 / task48.iea-shc.org

\section{Task 48}

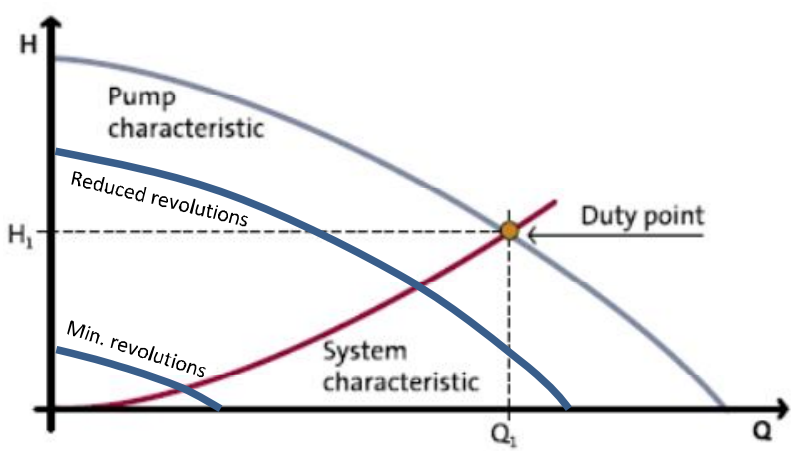

Figure 9: $\quad Q H$ map and system characteristic of a pump system. Based on: Pump handbook [6]

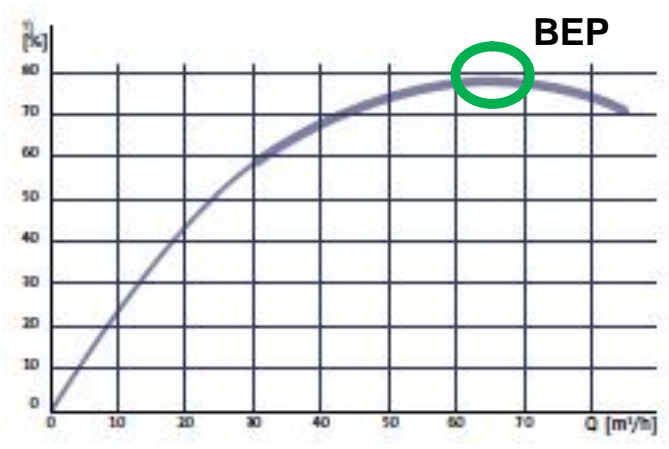

Figure 10: $Q H$ map and system characteristic of a pump system. Based on:Pump handbook [6]

\section{Efficiency, the $\boldsymbol{n}$ curve}

This important value $\eta$ gives the ratio between hydraulic power $P_{H}$ delivered to the heat carrier medium and the required either mechanical power at the shaft $\mathrm{P}_{2}$ (shafted rotodynamic pumps) or electrical power $\mathrm{P}_{1}$ to the pump (canned rotodynamic pumps). Important fact, if a shafted rotodynamic pump is applied the overall efficiency of the electric motor $\eta_{M}$ has to be taken into account additionally.

$$
\eta=\frac{P_{H}}{P_{1}}=\eta_{M} \frac{P_{H}}{P_{2}}=\eta_{F C} \cdot \eta_{M} \frac{P_{H}}{P_{2}}
$$

Furthermore if a frequency converter is used, its efficiency $\eta_{\mathrm{FC}}$ has to be incorporated as well.

Efficiency reaches its maximum in the so called BEP Best Efficiency Point for a single flow and head for which the pump was conceived. The duty point with most operating hours of the pump should match this point in order to get a good system performance over a wide range of flow conditions.

A general approach or rule of thumb to determine the efficiency of a hydraulic pump quickly is given in equation 8 , where $Q$ represents the flow of the heat carrier medium in $\mathrm{m}^{3} / \mathrm{h}$ and $\mathrm{H}$ the pump head in meter or converted pressure loss in the hydraulic loop respectively. Beside viscosity especially the density $\rho$ in $\mathrm{kg} / \mathrm{m}^{3}$ of the fluid affects electric power consumption $P_{1}$ in Watt and the overall efficiency $\eta$.

$$
\eta=\frac{Q \cdot H \cdot \rho}{367 \cdot P_{1}}
$$

Vice versa, the transformed equation 9 allows simple electricity consumption predication $P_{1}$ in Watt if flow $Q$ in $m^{3} / h$, pressure loss in the system $p$ in millibar and overall pump efficiency $\eta$ is known.

$$
P_{1}=\frac{Q \cdot p}{36 \cdot \eta}
$$




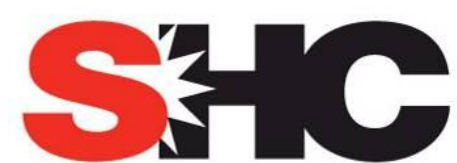

SOLAR HEATING \& COOLING PROGRAMME INTERNATIONAL ENERGY AGENCY

IEA SHC Task 48 / task48.iea-shc.org

\section{Task 48}

\section{Electric power consumption, $\mathbf{P}_{1}$ - curve}

Most of the power consumption curves are similar to the given one in Figure 11. There's one very import aspect to be watched out. While for canned pumps in general (but not always) $P_{1}$ is shown, shafted always give $\mathrm{P}_{2}$ as power input to the crank.

$\mathrm{P}_{1}$ Electricity consumed by whole pumping system including Inverter, circuit box, electric motor a.s.o

$\mathrm{P}_{2}$ Mechanical power to the shaft of the pump (shaft power)

$\mathrm{P}_{\mathrm{H}} \quad$ Hydraulic power performed to the fluid (useful energy)

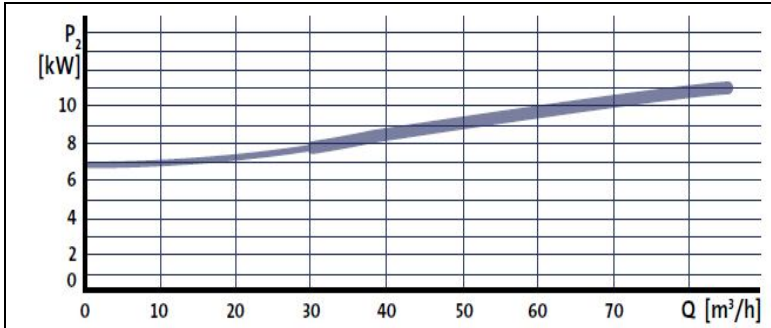

Figure 11: Electric power consumption curve [6]

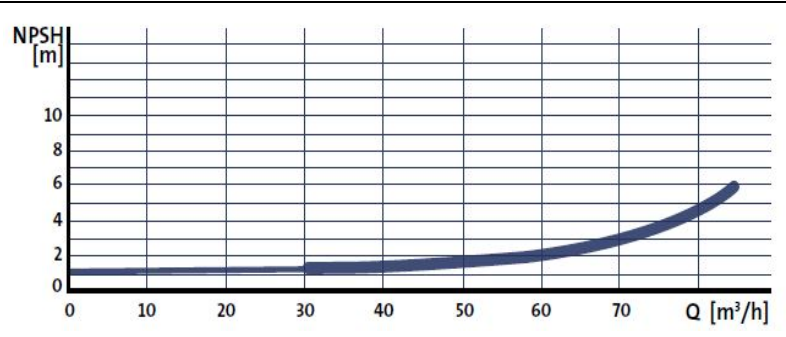

Figure 12: Net positive Suction Head NPSH [6]

\section{NPSH-curve (Net positive Suction Head) and Cavitation}

This value is crucial for a durable and safe operation of any pump. Especially at high temperatures e.g. Solar collector or chiller driving heat circuit at high flow conditions (increasing dynamic pressure) the static pressure at the inlet of the volute has to be higher than the boiling temperature of the heat carrier medium to prevent cavitation. Cavitation occurs somewhere at the back of the impeller vanes when the local static pressure is lower than the vapor pressure of the liquid. It results in reduced efficiency on the one hand, but more important might damage the pump over a longer period of time. Sufficient system pressure and a short link with low pressure loss between suction side and expansion vessel are very important design criteria. 


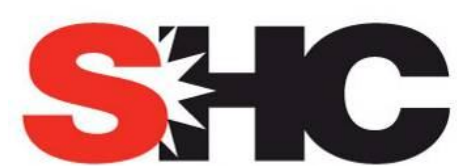

SOLAR HEATING \& COOLING PROGRAMME INTERNATIONAL ENERGY AGENCY

IEA SHC Task 48 / task48.iea-shc.org

\section{Task 48}

\section{Pump Adaptability and Control - Practical -}

This section deals with advanced control strategies and the adaptability of pumps to part load conditions, in order to improve the overall system performance. As variable speed control is the only choice for efficient and dynamic pump adaption to part load conditions, outdated methods like throttle or bypass control are not discussed.

\subsection{Communication and control}

A simple way is to switch the power ON and OFF. In some cases older high-efficiency pumps and switching relays have been destroyed due to the high initial current during the first Milliseconds to charge capacitors. In so doing, a big advantage is to avoid standby electricity consumption caused by the electronic of high-efficiency pumps or frequency converters.

If a speed control has to be applied most of the canned high-efficiency pumps allow 0-10 Volt or PWM signals for rotary speed adjustment and a dry contact for start/stop commands. In most of the canned high-efficiency pumps a part load adoption by constant or proportional differential pressure measurement is already implemented.

The next generation of high-efficiency pumps already feature a BUS-Communication module, allowing bidirectional communication and internal pump sensor detection for temperature regulated speed adjustment or heat metering.

Communication with Pumps via bidirectional BUS-Communication e.g. via GeniBUS protocol (provided by GRUNDFOS) or CANopen (provided by WILO)

Main advantages:

+ Reduced Wiring (Only BUS cable and Power Cable needed)

+ Free communication protocol (RS485)

+ Integrated measuring equipment provides additional data (Flow, head, speed, electricity consumption, temperature...) for part load adaption and performance evaluation

+ "Intelligent pumps" might replace most of the measuring equipment needed

Main problems:

- Possible but complex and not recommended for plumbers on-site

- Some measuring values are calculated and therefore not precise under extreme part load conditions

- Standby electricity consumption is increased

By now, intelligent high-efficiency pumps offer a great opportunity for advanced system evaluation at concurrently reduced measuring equipment. Due to its complexness and various interactions between several components, implementation will be reserved for manufacturers or prefabricated system providers. 


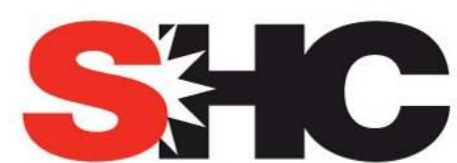

SOLAR HEATING \& COOLING PROGRAMME INTERNATIONAL ENERGY AGENCY

IEA SHC Task 48 / task48.iea-shc.org

\section{Task 48}

\subsection{Pump control strategies}

In this section different control strategies and the adaptation to part load conditions based on operational experience and system simulations are discussed briefly. A plus indicates an advantage either on system performance or simplified design, whereas a minus lists all negative aspects.

\section{Solar Primary Pump}

- Constant speed + simple control signal ON/OFF

+ ensures constant heat transfer values in the heat exchangers and collector

- decreases EER in part load conditions significantly

- rotary speed control to assure a constant OUTLET temperature at the solar collectors

+ constant driving heat temperature to chiller

+ increases EER in part load conditions

+ best choice if collector array feeds directly the heat buffer

- might suffer under oscillation behavior in connection with corresponding solar secondary pump control strategy

- rotary speed control in relation to the direct insolation on the aperture area

+ direct and independent reference to available solar heat

+ no time delay or dead time

+ ensures constant temperature difference

- additional insolation sensor needed

Solar Secondary Pump (obsolete if freeze protection is not in question)

- Constant

+ simple control signal ON/OFF

+ ensures constant alpha values in the heat exchanger

- decreases EER in part load conditions

- variable driving heat temperature leads to inefficient sorption process

- rotary speed control to assure a constant OUTLET temperature of the solar collectors

+ ensures constant buffer tank and driving heat temperatures

+ increases EER in part load conditions

- rotary speed control related to mass flow in primary solar collector circuit

- leads to oscillating behavior

Driving Heat Pump

- Constant

+ simple control signal ON/OFF

+ ensures constant alpha values in the heat exchanger

- decreases EER in part load conditions

- rotary speed control related to the chilled water capacity

- Capacity metering needed

+ increases EER in part load conditions) 


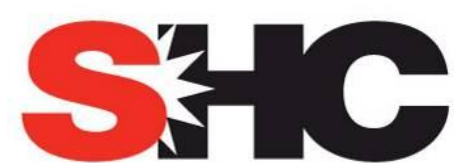

SOLAR HEATING \& COOLING PROGRAMME INTERNATIONAL ENERGY AGENCY

IEA SHC Task 48 / task48.iea-shc.org

\section{Task 48}

- rotary speed control related to driving heat temperature

- oscillating behavior in combination with driving heat mixing valve

\section{Primary Reject Heat Pump}

- Constant

+ simple control signal ON/OFF

+ ensures constant alpha values in the heat exchanger

- decreases EER in part load conditions

- rotary speed control to assure a constant OUTLET temperature of cooling water leaving the sorption machine

- might interact with cooling tower fan and influence chilled water capacity as well as driving heat regulation

- rotary speed controlled in relation to the chilled water capacity

- Capacity metering needed

+ increases EER in part load conditions

Secondary Reject Heat Pump

- Constant

+ simple control signal ON/OFF

+ ensures constant alpha values in the heat exchanger

- decreases EER in part load conditions

- rotary speed control in relation to the control signal of the primary reject heat pump

+ increases EER in part load conditions

+ simple control signal

- sometimes a mismatch occurs if pump performance curves and hydraulic characteristic differs in both circuits

- rotary speed controlled in relation to the primary rejected heat circuit flow + increases EER in part load conditions (best choice)

Chilled Water Pump

- Constant

+ simple control signal ON/OFF

+ ensures constant alpha values in the heat exchanger

- decreases EER in part load conditions

- may result in improper chilled water temperatures

- rotary speed control related to differential pressure drop at the cold distributor

+ increases EER in part load conditions

- rotary speed controlled related to chilled water mass flow needed

+ increases EER in part load conditions

- additional sensor required 


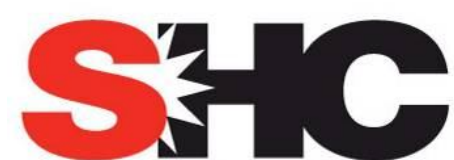

SOLAR HEATING \& COOLING PROGRAMME INTERNATIONAL ENERGY AGENCY

IEA SHC Task 48 / task48.iea-shc.org

\section{Task 48}

- rotary speed controlled to ensure a constant OUTLET temperature - may affect the capacity control of the chiller

Basically, if a variable speed control shall be applied, first clarify minimum or required flow-rates through the components in consultation with the manufacturer. Especially the sorption machine often requires a minimum flow in the chilled water circuit. Moreover some open wet cooling towers demand a certain pressure at the distribution nozzles. 


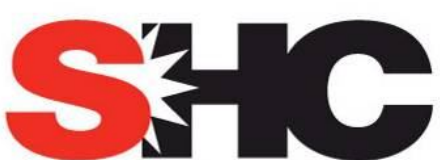

SOLAR HEATING \& COOLING PROGRAMME INTERNATIONAL ENERGY AGENCY

IEA SHC Task 48 / task48.iea-shc.org

\section{Task 48}

\subsection{Operating points and overall efficiency under real operating conditions}

The deployment of high-efficiency pumps in solar cooling installations does not implicate an efficient pumping automatically. In this section the operating point of rotodynamic pumps in the hydraulic circuits of two real applications are analyzed and discussed.

First SHC system example compromises a $7.5 \mathrm{~kW}$ Adsorption chiller with dry heat rejection plus water injection system located in Perpignan, France. A collector aperture surface of $25 \mathrm{~m}^{2}$ provides hot water which is fed into a buffer by means of the solar primary pump (Grundfos TP25-90/2). This shafted highefficiency pump possesses a maximum efficiency of $50 \%$ in its best operating point (BEP) as shown in Figure 13. Due to high pressure losses in the piping and collectors the real operating point is far left towards higher head and lower flow conditions $\left(Q=1.1 \mathrm{~m}^{3} / \mathrm{h}\right)$. Thus the real total efficiency $\eta_{\text {total }}$ reaches only $22 \%$ whereby about 110 Watts of electricity are consumed to supply solar heat to the buffer tank. Analogous, another similar circulator provides a hot water flow-rate of $1.6 \mathrm{~m}^{3} / \mathrm{h}$ to the generator of the adsorption chiller. Higher flow-rate at comparable head induces higher hydraulic power, but pumping efficiency increases in this case to $30 \%$ so that about 120 Watts of electricity are consumed. The cooling tower is linked to the adsorption chiller by short pipework filled with propylene glycol water mixture. Under best conditions the double-stage cooling water pump (Grundfos TP32-150/2) offers $37 \%$ overall efficiency. As real operating point is near the Best Efficiency Point about 370 Watts suffice to drive the heat carrier medium. Finally, another pump (Grundfos TP25-50/2) is needed to overcome the head loss between evaporator and cold water buffer in the chilled water circuit. Therefore about 110 Watts of electricity are consumed.

In contrast, the cumulated required hydraulic power amounts to only 201 Watts.

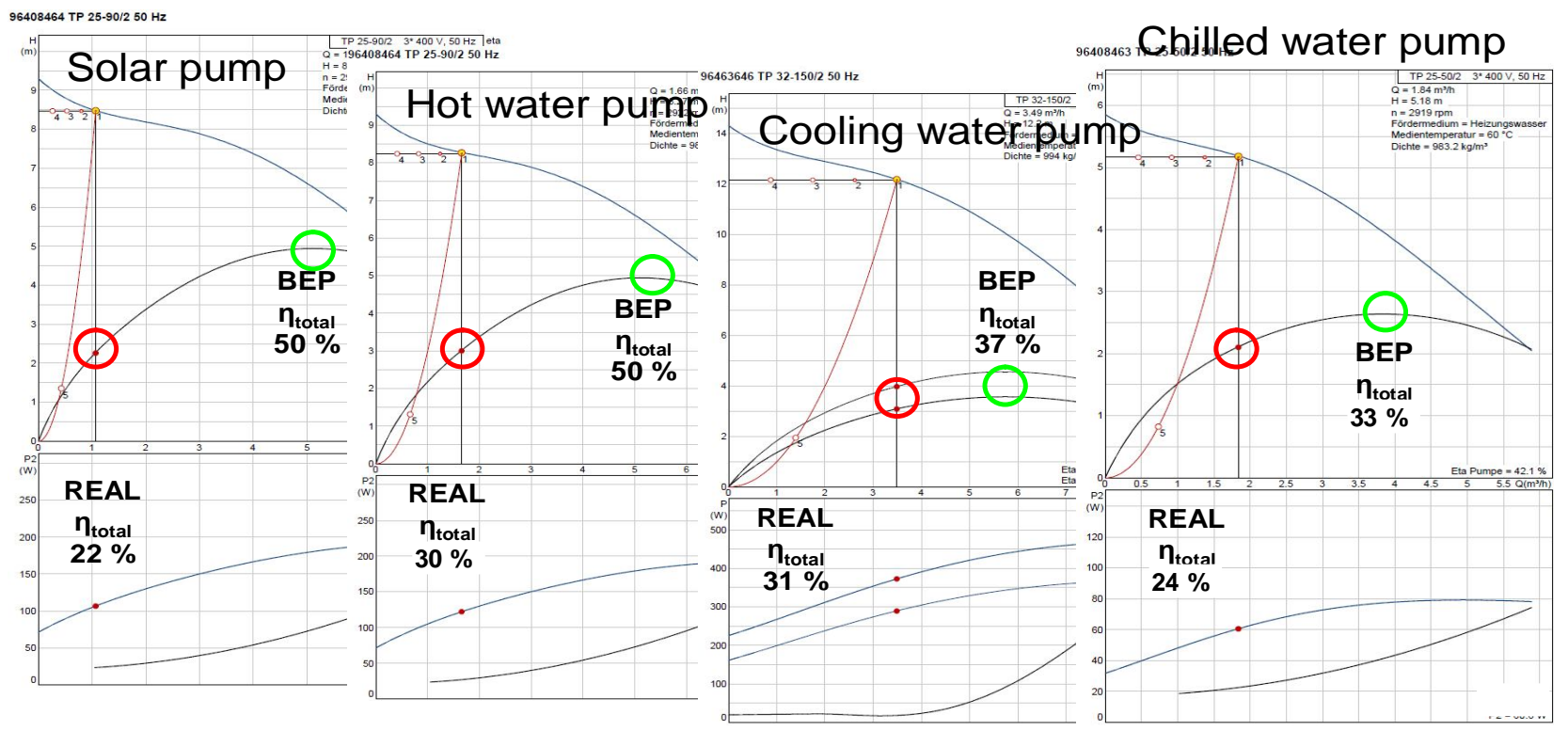




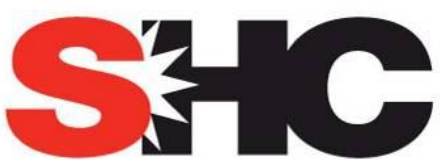

SOLAR HEATING \& COOLING PROGRAMME INTERNATIONAL ENERGY AGENCY

IEA SHC Task 48 / task48.iea-shc.org

\section{Task 48}

Figure 13: Characteristic $H Q$ and power diagrams with real operating points of circulators implemented in the hydraulic subsystems of a 7.5 chilled water capacity SHC system

Compendious, if the whole electricity consumption for pumping effort is summed up (710 Watts) and referred to the chilled water capacity $(7.5 \mathrm{~kW})$ the maximum EER of this scenario is calculated to 10.5 (ignoring other electricity consumers such as control, chiller internally, cooler fan a.so.) Without speed adjustment to part load conditions (e.g. $3.75 \mathrm{~kW}$ chilled water capacity) the overall electricity consumption of pumps is unaffected, leading to proportional reduced EER.

The second example comes with canned high-efficiency circulators, mostly adaptable to part load conditions by proportional adjustment of their rotary speed.

In order to drive the $10 \mathrm{~kW}$ Absorption chiller a $57 \mathrm{~m}^{2}$ flat plate solar collector array provides solar heat to a buffer (2000 Liters) via primary (water propylene glycol mixture) and secondary (water) hydraulic circuit. While the speed of the primary pump (Grundfos Magna 25-100) is adjusted in accordance with the insolation in collector plane, the secondary solar pump ensures a constant supply temperature to the buffer. Figure 14 shows the characteristic $H Q$ and $\mathrm{P}_{1}$ diagram (light blue section) of the primary solar collector pump and its operating points at design point (100\% Load) and minimum part load.
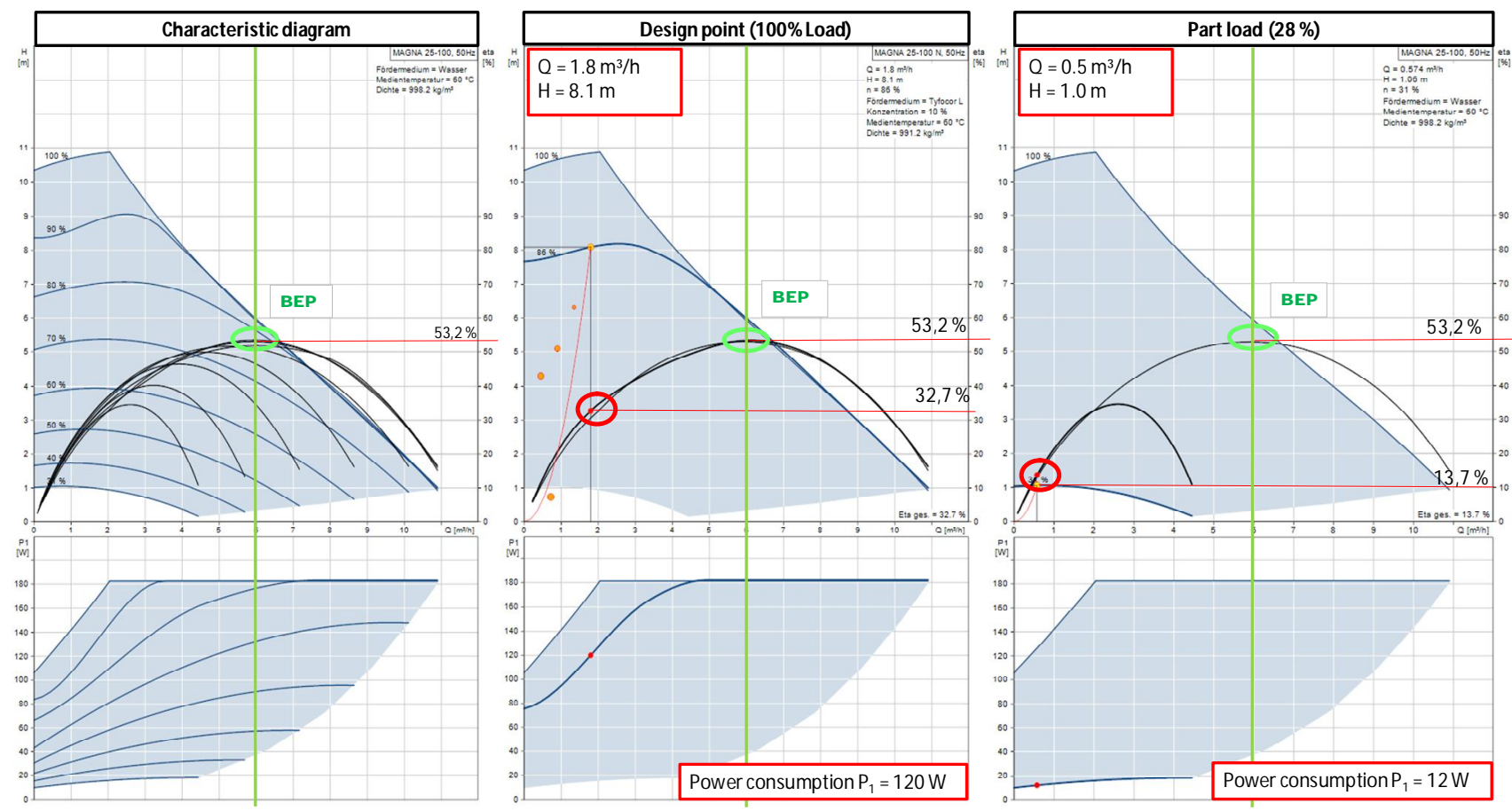

Figure 14: Characteristic $H Q$ and power diagrams of solar primary pump and its operating points

A maximum efficiency of $53.2 \%$ is achievable at Best Efficiency Point (BEP) of this pump. Similar to the prior example the real operating point $\left(\mathrm{Q}=1.8 \mathrm{~m}^{3} / \mathrm{h}\right.$ ) is far left resulting in reduced conversion efficiency of only $32.7 \%$. During minimal part load conditions $\left(\mathrm{Q}=0.5 \mathrm{~m}^{3} / \mathrm{h}\right)$ it even drops down to 13.7 $\%$. However, the high dynamic of 3.6 in flow-rate $\left(1.8\right.$ compared to $0.5 \mathrm{~m}^{3} / \mathrm{h}$ ) allows a proportional speed adaption between 100 and $28 \%$ load. Despite decreasing pump efficiency the specific electricity consumption is disproportionately reduced from 120 Watts to 12 Watts respectively. 


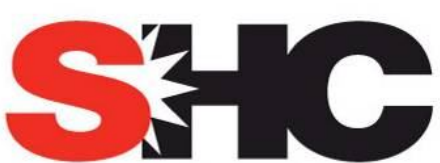

SOLAR HEATING \& COOLING PROGRAMME INTERNATIONAL ENERGY AGENCY

IEA SHC Task 48 / task48.iea-shc.org

\section{Task 48}

Analogous, the solar secondary circuit pump (WILO-Stratos 25/1-5 BMS) provides a maximum efficiency of 30.9 in contrast to the real value of 25.9 at design point $\left(\mathrm{Q}=1.4 \mathrm{~m}^{3} / \mathrm{h}\right)$. Likewise, efficiency drops down to $12.5 \%$ in part load conditions at $\mathrm{Q}=0.9 \mathrm{~m} / \mathrm{h}$. Since this pump is oversized the dynamic range is limited to 1.6 , which leads to a constant electricity consumption of 12 Watts even below $62.5 \%$ part load conditions and 25 Watt at design point.

Due to a very low pressure loss through the generator and the pipework between the chiller and heat buffer the pumping effort is relatively small. For this case, a constant speed pump (Grundfos Alpha2 25-50) fits best, operating at almost optimum efficiency of $42.4 \%$ with a constant electricity consumption of 33.5 watt in total.

The cooling water circuit is divided in a primary water and a secondary water-glycol mixture circuit for freeze protection. Both pumps, primary (Grundfos Magna 25-100) and secondary (Grundfos Magna 32-100), actuate depending on the chilled water capacity between $100 \%$ and $38 \%$ of nominal flow.
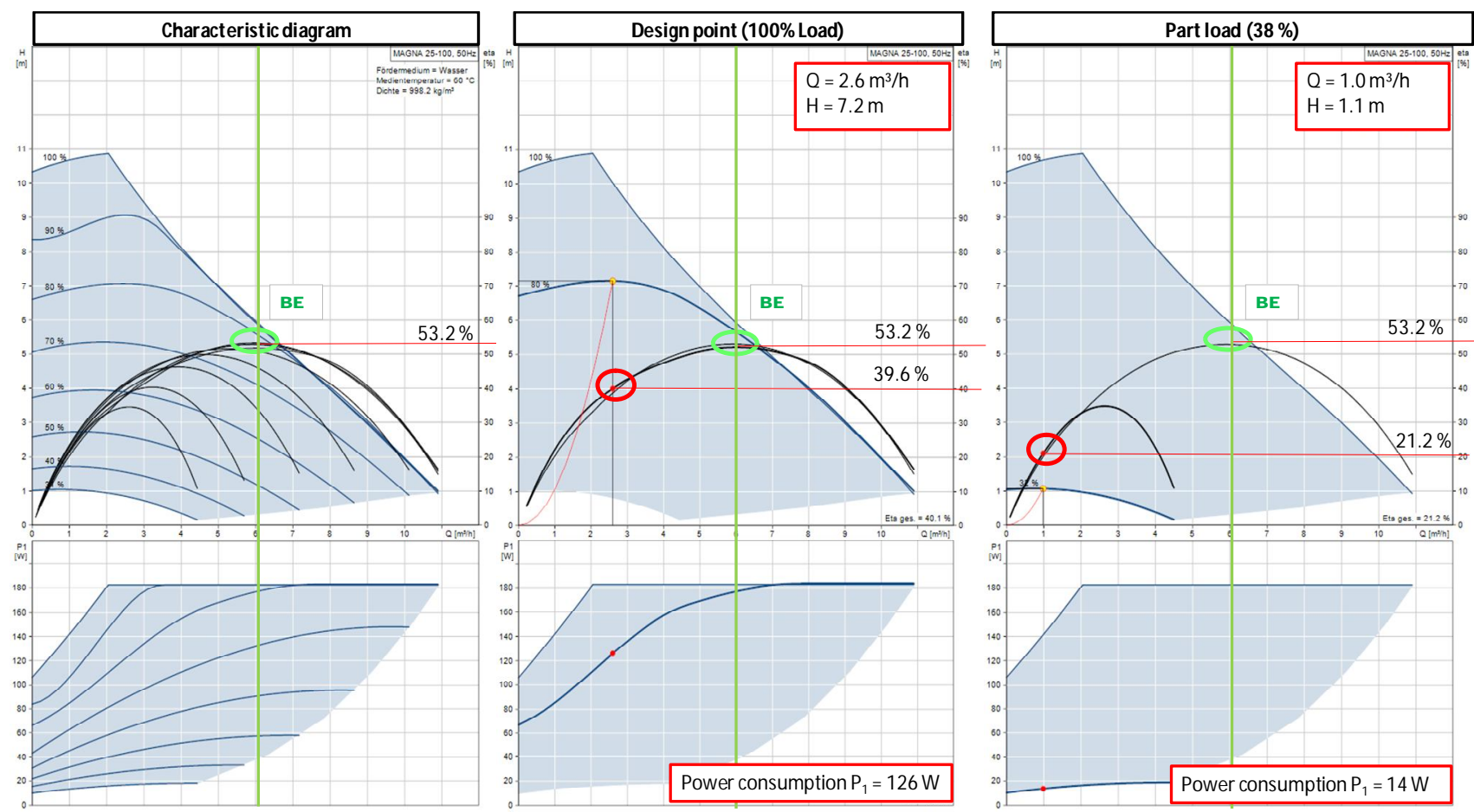


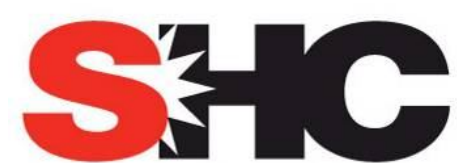

SOLAR HEATING \& COOLING PROGRAMME INTERNATIONAL ENERGY AGENCY

IEA SHC Task 48 / task48.iea-shc.org

\section{Task 48}
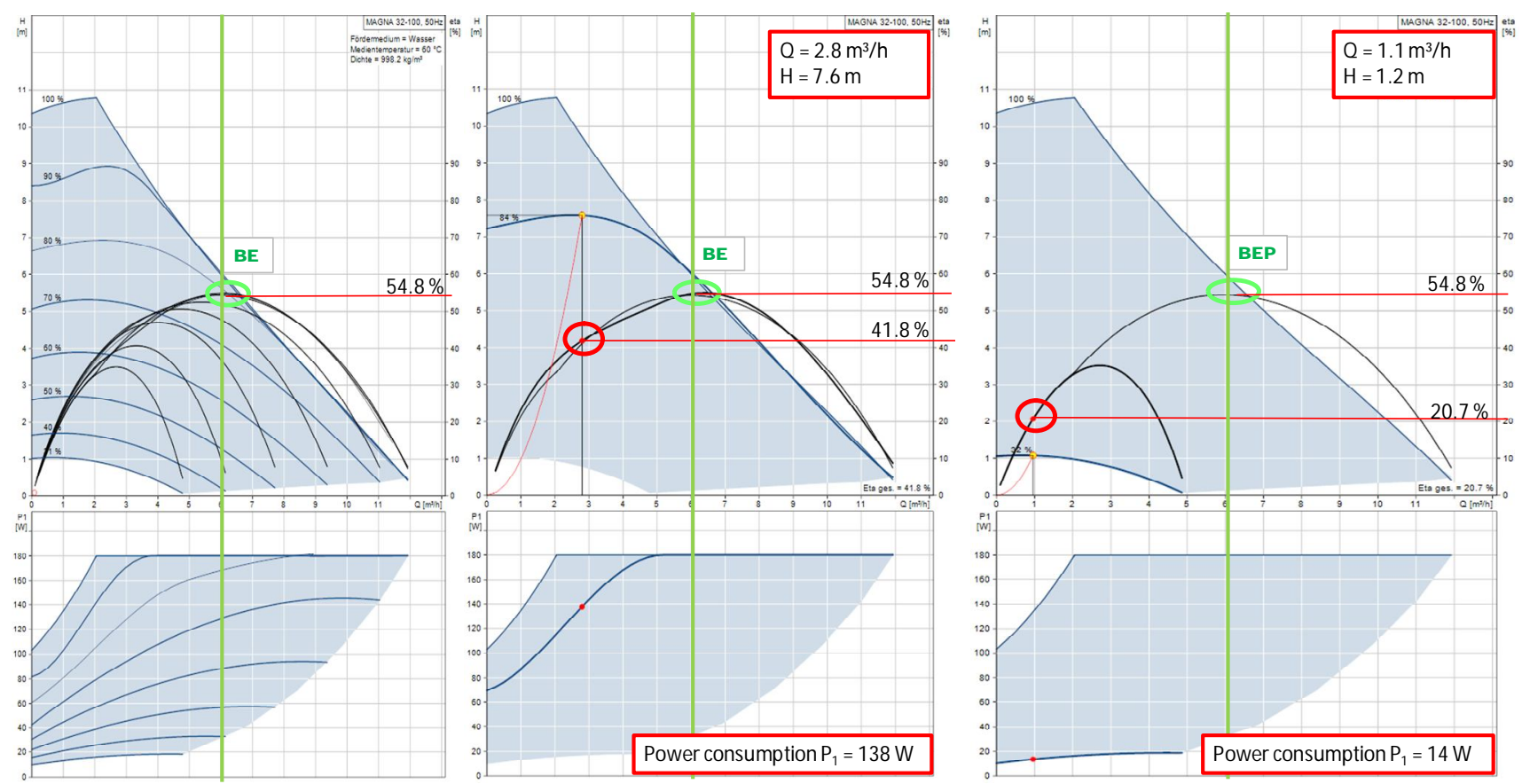

Figure 15: Characteristic HQ diagrams of primary and secondary pump in the cooling water circuit

Consolidated, at design point conditions 264 Watts are to spend for transferring rejected heat from the absorber to the cooling tower and at 38\% part load or lower constant 28 Watts, respectively.

The chilled water pump (Grundfos Magna 25-100) operates, differential pressure controlled, between Evaporator and cold distribution of the building. In this way, the pump modulates depending on the chilled water consumption or cooling demand respectively of the building. Furthermore, this reference input allows for speed adaption of cooling water circuit pumps and cooling tower fan to part load conditions. With a high dynamic ratio of 2.7 the chilled water pump operates with satisfying efficiency in a wide range. 


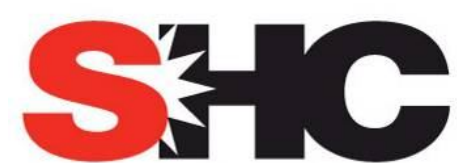

SOLAR HEATING \& COOLING PROGRAMME INTERNATIONAL ENERGY AGENCY

IEA SHC Task 48 / task48.iea-shc.org

\section{Task 48}
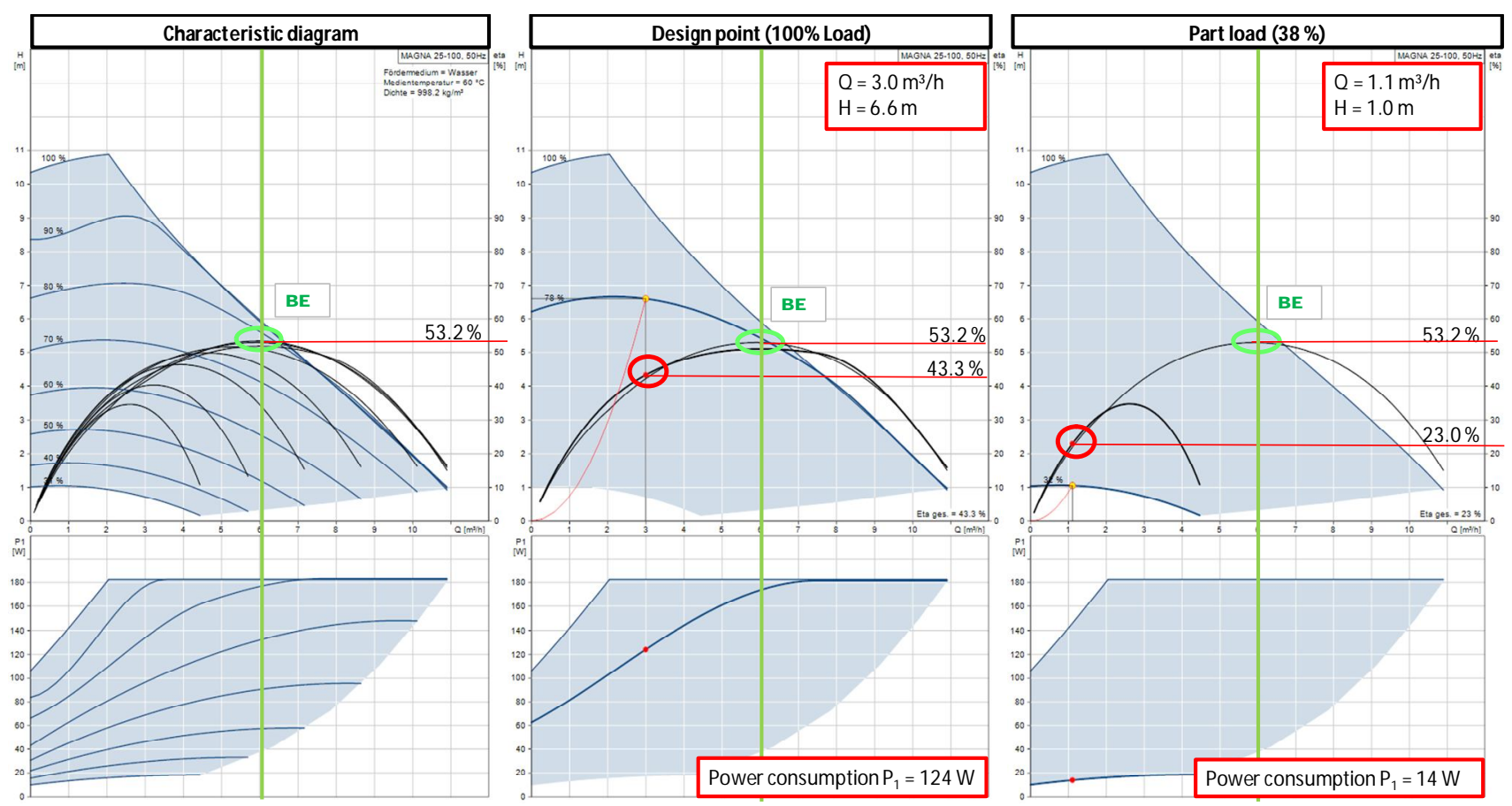

Figure 16: Characteristic $H Q$ and power diagrams of chilled water pump at different operating points

Compendious, the notional overall EER for $10 \mathrm{~kW}$ chilled water capacity including the electricity consumption of all pumps at design point (566.5 Watts) figures to about 17.6. Assuming a minimum part load capability of the absorption chiller around $2.5 \mathrm{~kW}$ chilled water capacity (25\% part load), the overall electricity consumption caused by circulators remains at 99.5 watts. Consequently the EER referred to pump work increases to 25 despite worse conversion factors.

\section{Conclusion:}

Although, even small high-efficiency pumps feature high conversion efficiency between electricity and hydraulic power the practical operating point is often far away from that optimum. A proper match of characteristic system and pump curve during design phase is essential. Furthermore if a high adaption to part load conditions is stipulated, a variable speed control at least of cooling water and chilled water pump is recommended. 


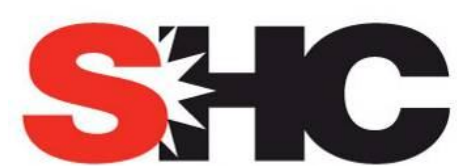

SOLAR HEATING \& COOLING PROGRAMME INTERNATIONAL ENERGY AGENCY

IEA SHC Task 48 / task48.iea-shc.org

\section{Task 48}

\section{Design Guidelines and Best Practice for Efficient Hydraulics}

Notwithstanding various design guidelines, handbooks and simplified system schemes dealing with optimized hydraulic design in SHC systems a proper and well performing installation is still a question of experience or pre-fabrication. The complexity and interaction of many different units cause a high on-site planning effort including multiple error sources. Determinative aspect is a correct pressure loss calculation and review of the overall auxiliary electricity consumption as well as control strategy throughout the whole operating range. Subsequent, some main design aspects as well as recommended standard values for Auxiliary Energy Consumption Ratios are given.

\subsection{Guidelines for hydraulic design and pump selection}

- Reduce heat carrier flow through the main components, thus

- Prefer high temperature differences in the main circuits especially in the cooling water circuit where most of the electricity is consumed.

- Prefer chiller design with low pressure losses through internal heat exchangers,

- Reduce pipe length of water/glycol circuits to a minimum

- High thermal COP reduces driving and rejected heat quantity simultaneously and consequently pumping effort of heat carrier medium.

- Reduce pressure losses in the pipework (sharp edges, Valves, filters, etc.)

- Design pipe diameter to achieve heat carrier medium flow speed between 1 and max. $1.5 \mathrm{~m} / \mathrm{s}$ for medium sized SHC-Systems

- Select the operating point of pumps lightly right from Best Efficiency Point in the Sweet or Happy zone to achieve best pump efficiency at part load conditions

- Avoid high head and multi-stage pumps as each additional stage reduces the overall efficiency

- High-efficiency pumps are highly recommended, at least for chilled water and cooling water circuit

- Pump speed related to variable heat flow ensures high performance in a wide operating range

- Continuous review of AECRs during system operation exposes malfunctions promptly

Recommended standard values of AECR in order to achieve a good seasonal system performance.

AECR at design point and even better under part load conditions

$\begin{array}{ll}\text { AECR }_{\text {Solar }} & \sim 150 \\ \text { AECR }_{\text {Backup }} & \sim 250 \\ \text { AECR }_{\text {D }} & \sim 250 \\ \text { AECR }_{\text {AC }} & \sim 100 \\ \text { AECR }_{\text {cooler }} & \sim 100 \\ \text { AECR }_{\text {E }} & \sim 80 \\ \text { AECR }_{\text {chiller }} & \sim 150\end{array}$




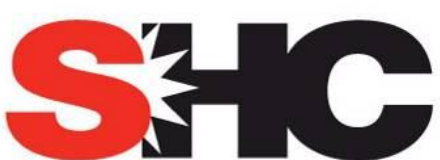

SOLAR HEATING \& COOLING PROGRAMME INTERNATIONAL ENERGY AGENCY

IEA SHC Task 48 / task48.iea-shc.org

\section{Task 48}

\subsection{Best practice and successful optimization of solar cooling system}

Among others, the SHC System at ZAE Bayern could benefit from a detailed scientific supervision and optimization over more than 3 years. This small scale solar cooling and heating installation erected in 2007 comprises a $10 \mathrm{~kW}$ cooling capacity absorption chiller with dry heat rejection supported by a latent heat storage. Solar heat is harvested by a common flat plate collector array of $57 \mathrm{~m}^{2}$ aperture surface and delivered to a 2000 Liter hot water buffer. Figure 17 lists the whole number of electricity consumers. Starting in 2010 the overall electricity consumption at design point had been calculated to 1345 Watts. Over the following years several optimization phases took place.

As a first step, low efficient circulators of the solar primary and secondary as well as hot water driving circuit had been replaced by high-efficiency pumps. Furthermore oversizing had been eliminated. Thus, an abated overall electricity consumption of about 1117 Watts had been obtained. Subsequent optimization concentrated on fan efficiency and standby auxiliary energy consumption, resulting in a minor effect on system efficiency. In 2012 a revision of the absorption chiller parameters raises thermal COP and temperature difference in the driving hot water circuit, by which means the required flow-rate and heat dissipation to the ambient decreases. Additionally, a revised chilled water pump speed control is applied. Currently the electricity consumption at design point conditions totals to 732 Watts. Because of continual system optimization the Seasonal performance factor SPF_el,tot of this SHC System improved from 7.9 in 2010 to 12.07 in 2012.

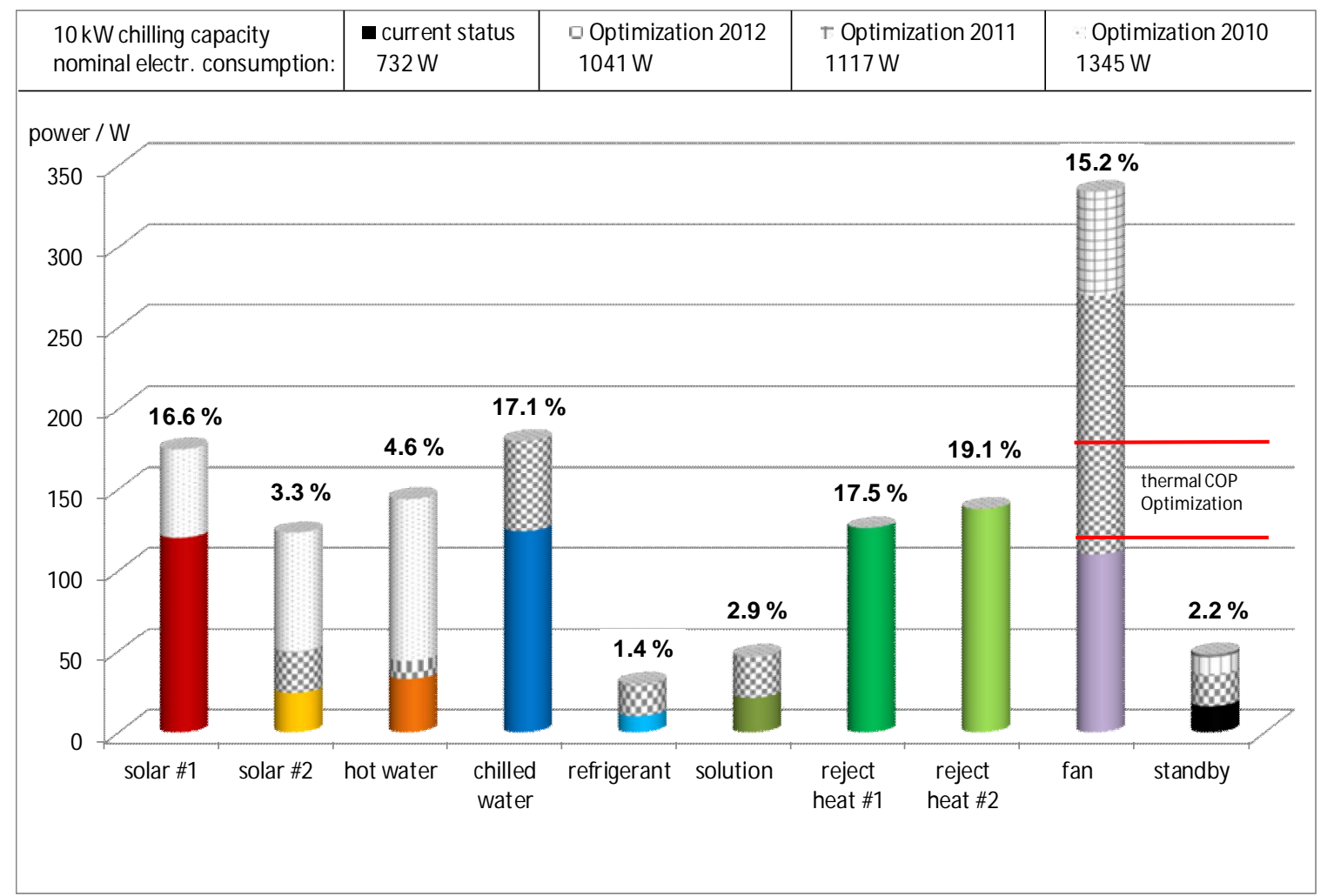

Figure 17: Distribution of auxiliary energy consumption and stepwise optimization results 


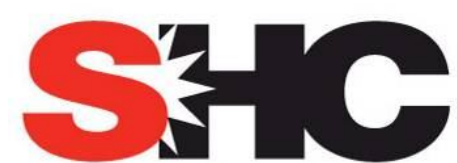

SOLAR HEATING \& COOLING PROGRAMME INTERNATIONAL ENERGY AGENCY

IEA SHC Task 48 / task48.iea-shc.org

\section{Task 48}

The following Figure 19 and Figure 20 show the overall system performance key figures thermal and EER for the selected SHC system during the cooling period 2013. In addition to that, relevant boundary conditions such as cumulated daily insolation on collector plane and maximum, minimum and average ambient air temperature are given in Figure 18.

Ins olation / k Wh: $\mathrm{m}^{-2}$

2013

Ambient temperature $/{ }^{\circ} \mathrm{C}$

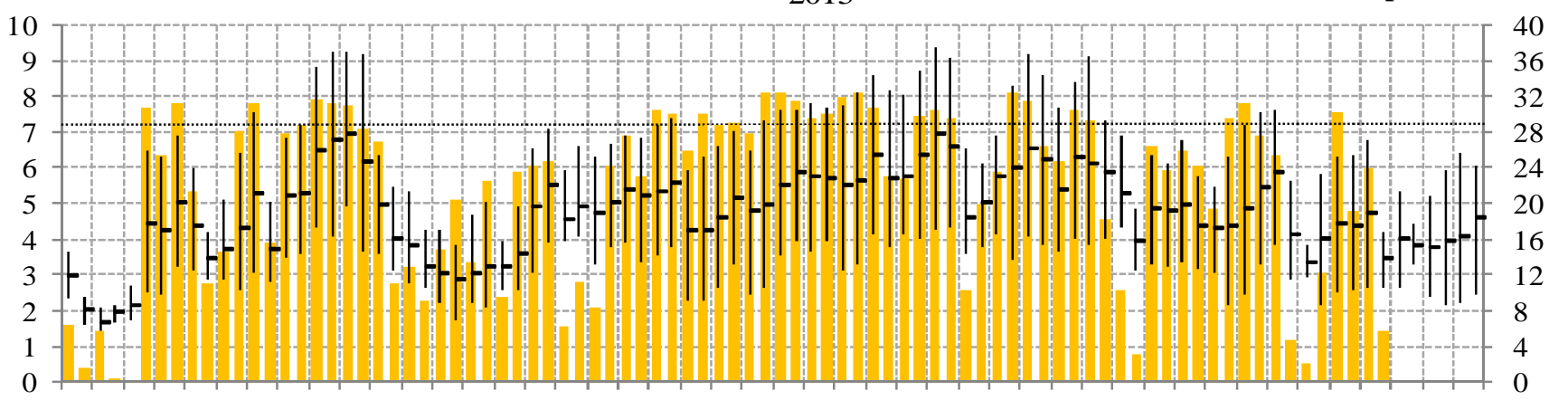

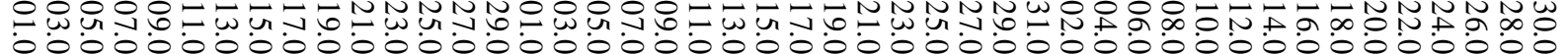

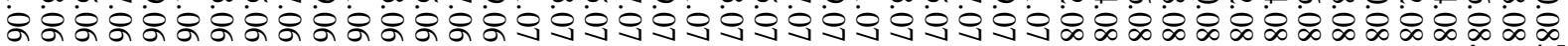

time / dd:mm

Figure 18: Daily insolation on collector surface and ambient temperatures (max, min, average)

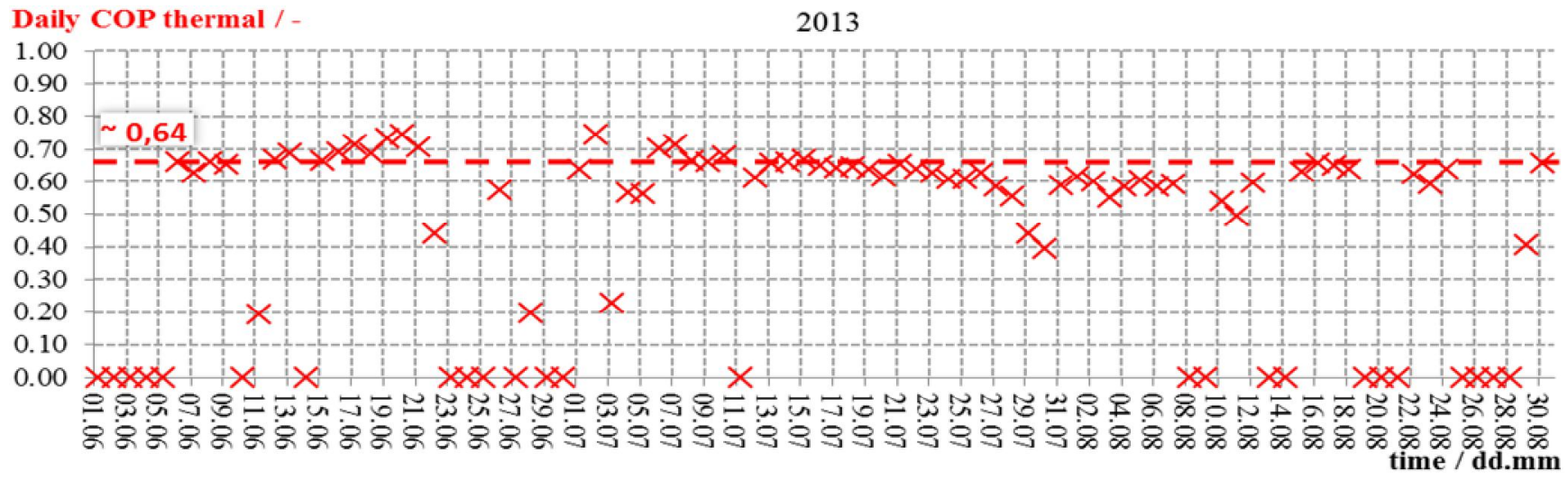

Figure 19: Daily thermal COP including start up and shutdown phases 


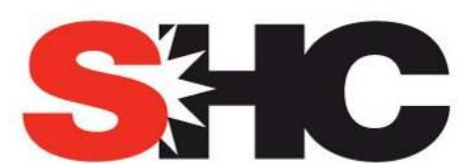

SOLAR HEATING \& COOLING PROGRAMME INTERNATIONAL ENERGY AGENCY

IEA SHC Task 48 / task48.iea-shc.org

\section{Task 48}

2013

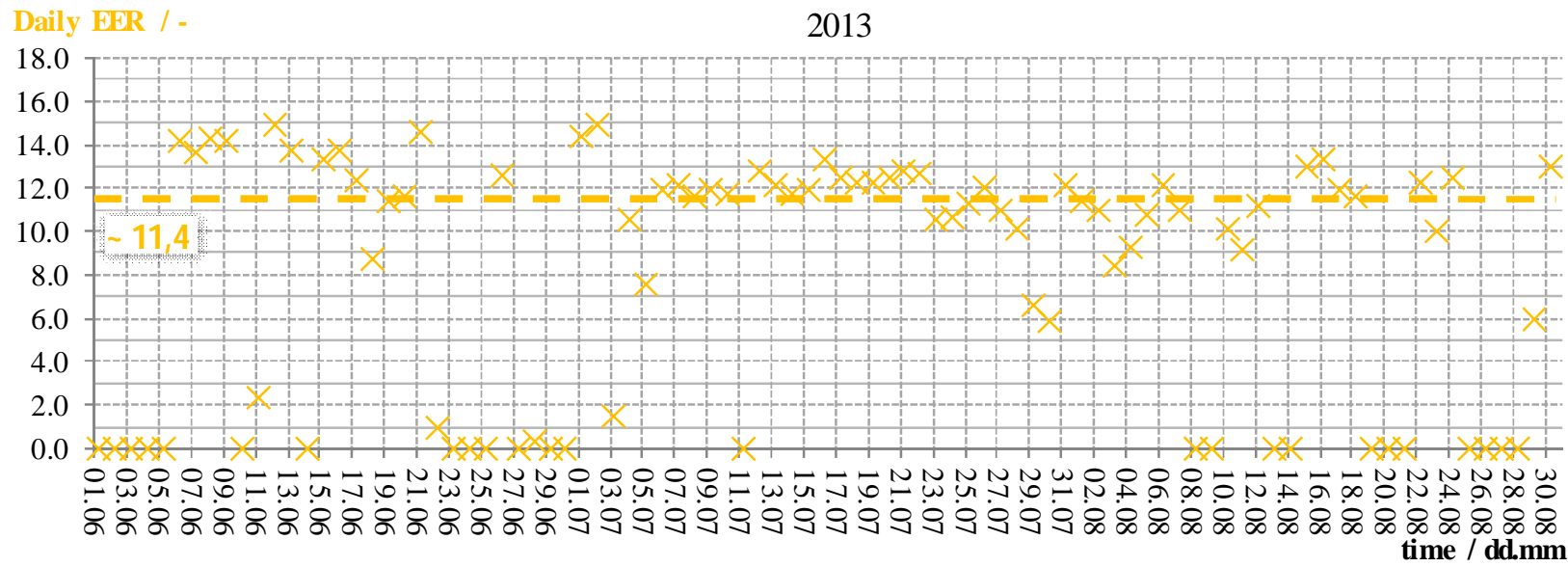

Figure 20: Daily EER for chilled water production including all electricity consumer of the SHC System

Expect for a few days, with little operating hours of the chiller, the thermal COP reaches a seasonal average of 0.64 and the seasonal EER for cooling averages to about 11.4.

Regarding pump and hydraulic circuit efficiency Figure 21 plots the daily AECR Solar as yellow dots in front of the daily cumulated insolation on collector plane and delivered heat to the heat buffer. In most cases with considerable solar gain the AECR Solar exceeds 150.

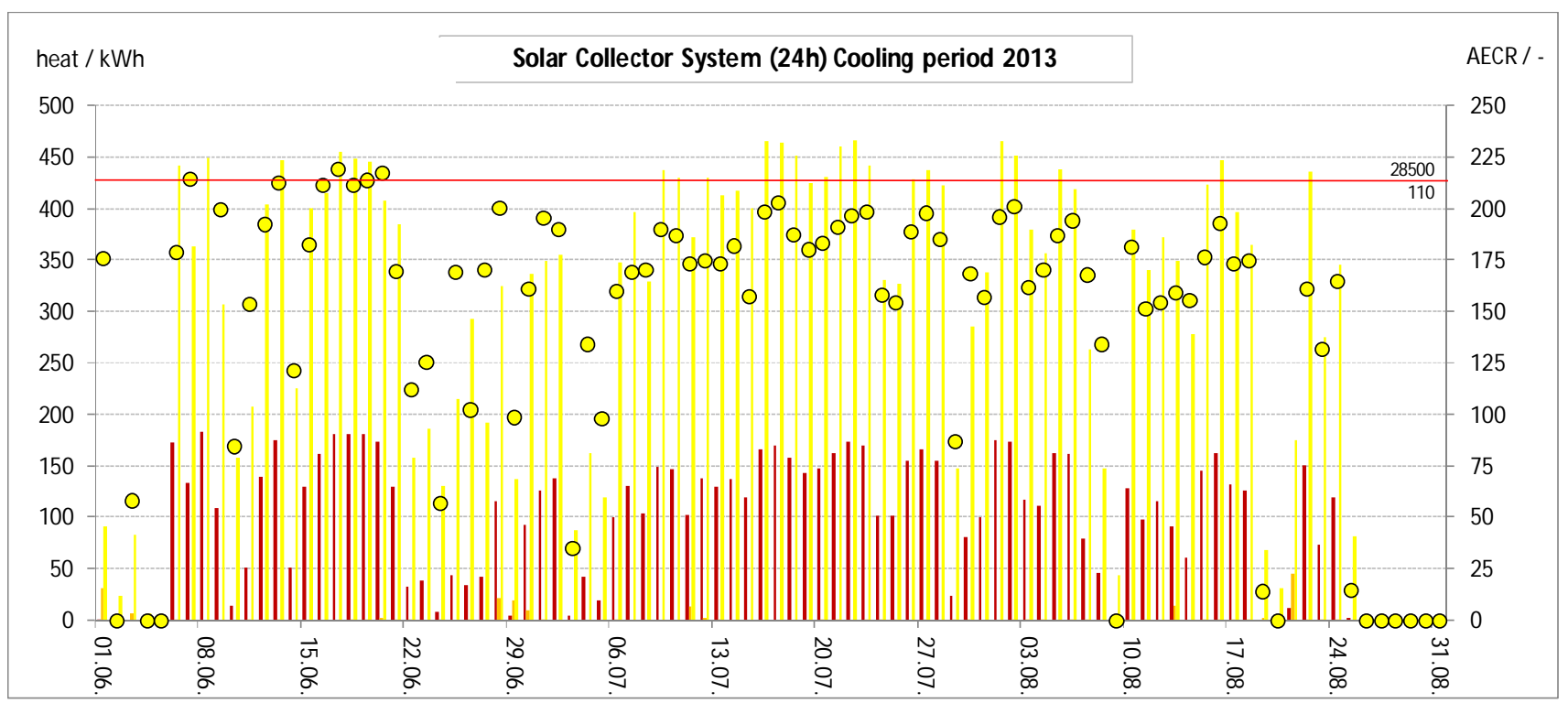

Figure 21: Daily auxiliary energy consumption ratios of the solar collector circuit 


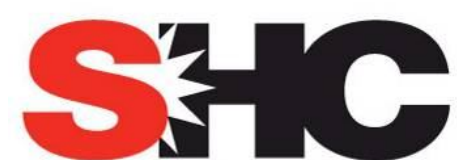

SOLAR HEATING \& COOLING PROGRAMME INTERNATIONAL ENERGY AGENCY

IEA SHC Task 48 / task48.iea-shc.org

\section{Task 48}

Further major auxiliary electricity consumers are primary and secondary pump of the cooling water circuit due to the high amount of rejected heat in single stage absorption chillers. Thus, a high temperature difference between cooling water supply and return reduces flow-rate and pumping effort accordingly. In addition to that, a proper design of the pipework with flow speeds below $1 \mathrm{~m} / \mathrm{s}$ and minimized length of the secondary circuit containing water propylene glycol mixture, in combination with variable pump speed at part load conditions, ensures an almost constant high $A E C R_{A C}$ above 100 as shown in Figure 22.

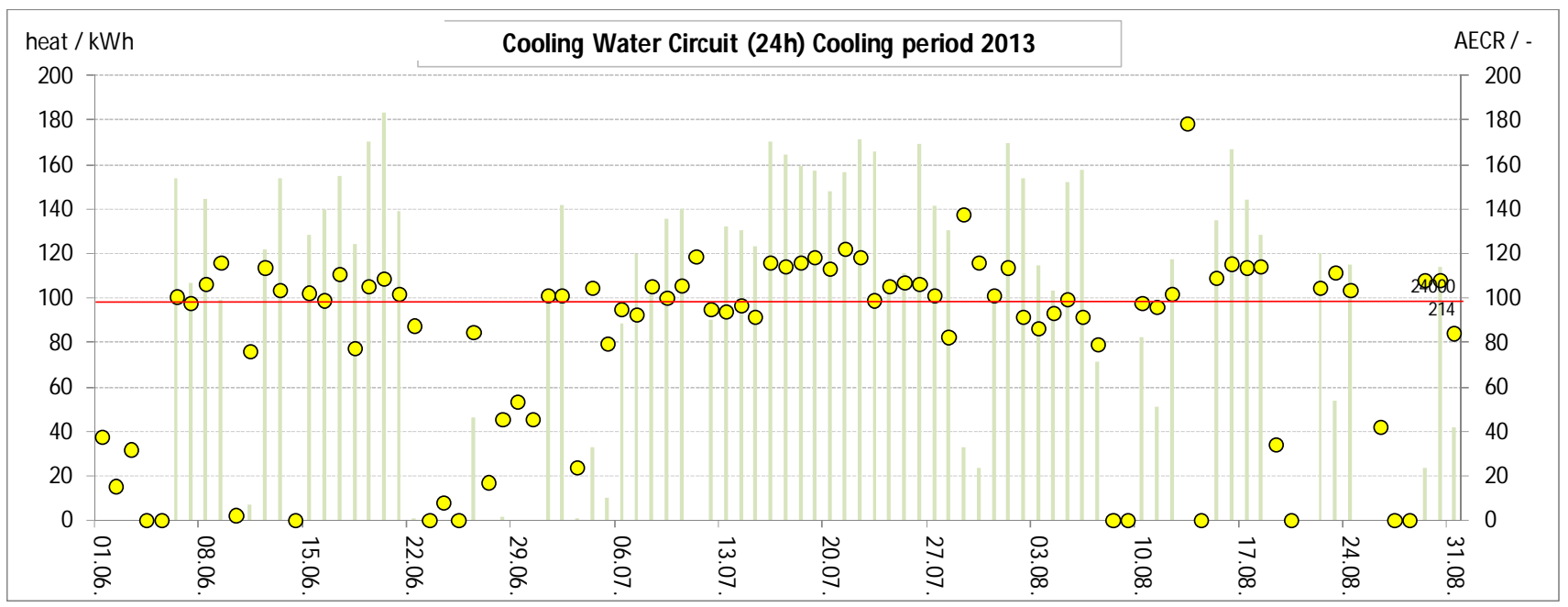

Figure 22: Daily auxiliary energy consumption ratios $A E C R_{A C}$ of the cooling water circuit 


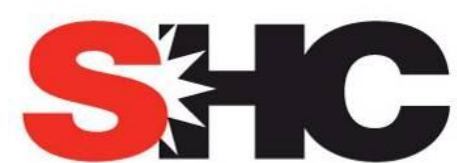

SOLAR HEATING \& COOLING PROGRAMME INTERNATIONAL ENERGY AGENCY

IEA SHC Task 48 / task48.iea-shc.org

\section{Task 48}

\section{Discussion and Conclusion}

Beside the electricity consumption of the cooling tower, auxiliary power in thermally driven SHC Systems is mainly dominated by pumping effort for heat transmission between the components. Since 2010 great improvements in overall pump efficiency have been obtained, in particular due to legislative restrictions and manufacturer initiatives. Depending on size, about $50 \%$ to $80 \%$ of the consumed electricity is converted into useful hydraulic power. But the utilization of high-efficiency pumps in solar cooling installations does not implicate an efficient pumping automatically. The strong relationship between characteristic pump and system curve demands a proper system design as well as pump selection.

Due to either huge heat quantity and/or small temperature difference the high specific auxiliary energy consumption in the chilled and cooling water circuit are dominating. Even though investment costs of a variable speed high-efficiency pump often is twice as high compared to a cheap, but inefficient fixed speed pump, the overall costs for pumps in SHC systems are rather small or often negligible. But the ability to adjust pump speed to part load conditions, especially in these hydraulic circuits, has a high impact on system efficiency regarding EER.

In addition to that, intelligent high-efficiency pumps featured with internal flow, pressure, temperature and power meter offer a great opportunity for advanced system evaluation at concurrently reduced measuring equipment. Theoretically, the potential savings of auxiliary energy for pumping effort under part load conditions are huge. Due to its complexity and various interactions between several components, implementation will be reserved for manufacturers or prefabricated system providers. Nevertheless, there are some SHC Systems which operate quite fine after some years of optimization.

The way things are an overall SEER for well-designed small scale solar cooling systems of 20 seems to be feasible. However, currently many sorption chiller manufacturers mainly focus on cheap chillers than good seasonal system performance. As the thermodynamic and hydraulic design criteria of the chiller defines the capacities, temperature levels and/or heat transfer medium flows in the entire solar cooling system their thermal design should be revised. 


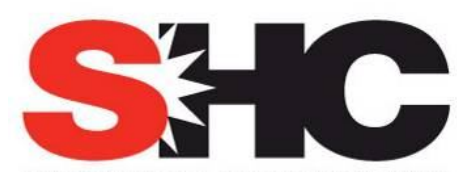

SOLAR HEATING \& COOLING PROGRAMME INTERNATIONAL ENERGY AGENCY

IEA SHC Task 48 / task48.iea-shc.org

\section{Task 48}

\section{References}

[1] European Comission, European Guide to Pump Efficiency for Single Stage Centrifugal Pumps, May 2003

[2] M. Becker, M Helm, C. Schweigler; Collection of selected systems schemes "Generic Systems" IEA Task38 D-A2; 2009

[3] A. Preisler, T. Selke, L. Sisó, A. LeDenn und R. Ungerböck, „ROCOCO - Reduction of costs of Solar Cooling systems," European Project in the 6th Framework Programme, TREN/05/FP6EN SO7.54855/020094, Specific Support Action, Vienna, 2008.

[4] D. Schall, S. Hirzel, (2012): Thermal cooling using low-temperature waste heat: a cost-effective way for industrial companies to improve energy efficiency? Energy Efficiency, 5, S. 547-569.

[5] N. Bidstrup, G. Hunnekuhl, H. Heinrich, T. Andersen; Classification of Circulators; Europump 2003

[6] Grundfos Industries, Grundfos Pump Handbook, Bjerringbro 2004

[7] Bachus, Larry and Custodio, Angel. Know and Understand Centrifugal Pumps. Amsterdam : Elsevier Science, 2003. ISBN 1856174093.

[8] Palgrave, Ron. Troubleshooting Centrifugal Pumps \& their system. Amsterdam: Elsevier Science, 2003. ISBN 1856173917.

[9] Turton, R.K. Rotodynamic Pump Design. Cambridge : Cambridge University Press, 1994. ISBN 052130502.

\section{Acknowledgements}

This work had been partly funded by the Federal Ministry for the Environment, Nature Conservation, Building and Nuclear Safety of Germany under grant number 0325982A. 